\title{
Enantioselective synthesis of heterocyclic compounds using photochemical reactions
}

\author{
Norbert Hoffmann ${ }^{1}$
}

Received: 27 September 2021 / Accepted: 6 November 2021 / Published online: 25 November 2021

(c) The Author(s), under exclusive licence to European Photochemistry Association, European Society for Photobiology 2021

\begin{abstract}
Different methods for the direct enantioselective photochemical synthesis of heterocycles are presented. Currently, asymmetric catalysis with templates involving hydrogen bonds or metal complexes is intensively investigated. Enzyme catalysis can be simplified under photochemical conditions. For example, in multi enzyme systems, one or more enzyme catalytic steps can be replaced by simple photochemical reactions. Chiral induction in photochemical reactions performed with homochiral crystals is highly efficient. Such reactions can also be carried out with crystalline inclusion complexes. Inclusion of a photochemical substrate and an enantiopure compound in zeolites also leads to enantioselective compounds. In all these methods, the conformational mobility of the photochemical substrates is reduced or controlled. Memory of chirality is a particular case in which a chiral information is temporally lost but the rigid conformations stabilize the molecular structure which leads to the formation of enantiopure compounds. Such studies allows a profound understanding on how particular conformations determine the configuration of the final products.
\end{abstract}

Extended author information available on the last page of the article 


\section{Graphical abstract}

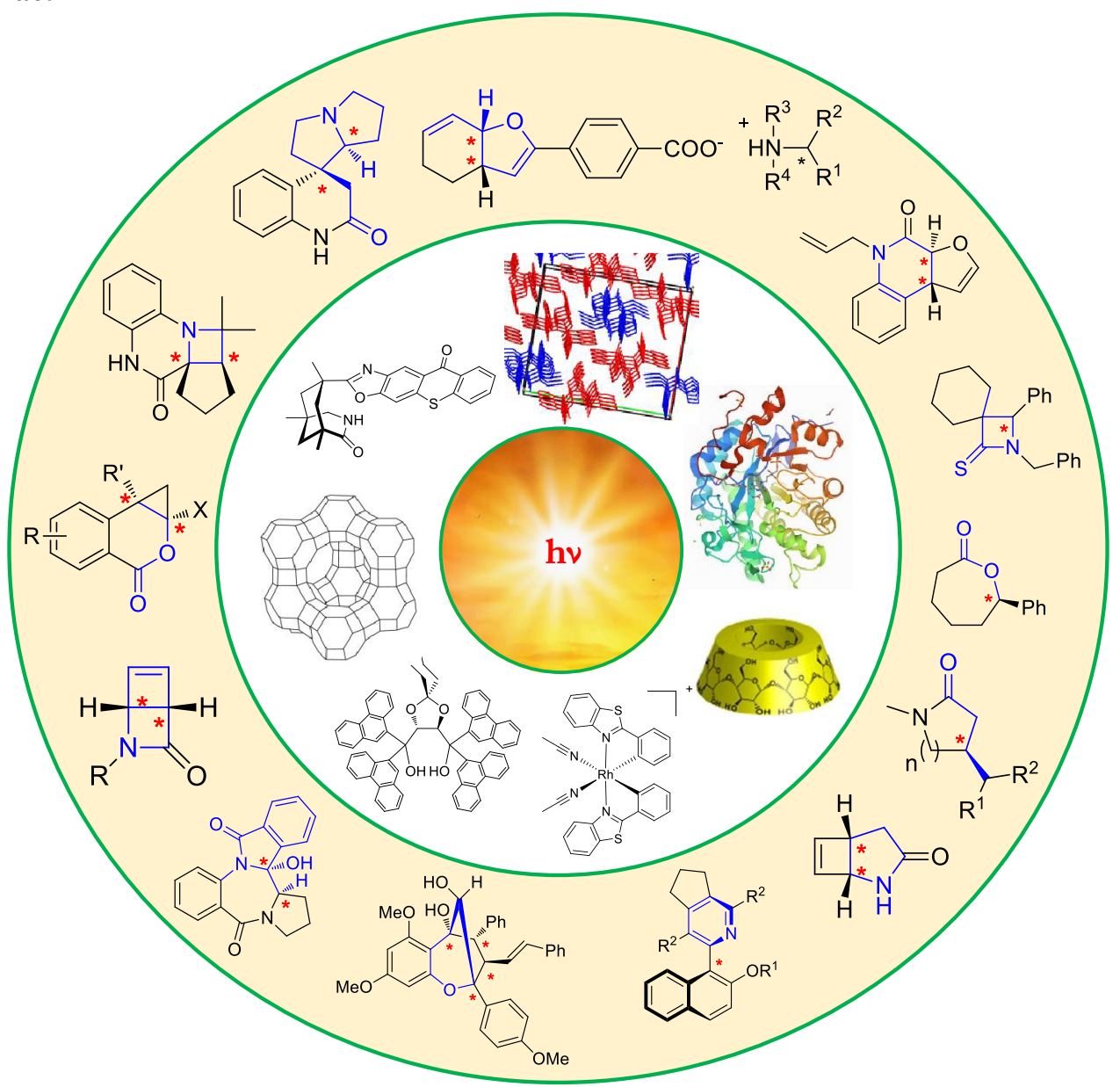

\section{Introduction}

Photochemical reactions play a key role in organic synthesis methodology [1-3]. In this regard, the reactions are particularly interesting because new compounds or compound families become available or more easily available. This significant extension of the chemical structure space or the molecular diversity [4-7] is due to the fact that photochemical excitation considerably modify the reactivity of chemical compounds [8-10]. High molecular diversity and complexity is of high interest in the pharmaceutical chemistry and agrochemistry where new biologically active compounds are searched [11-13]. Many other domains such as material science, for example organic semiconducting materials [14] are also concerned. Heterocyclic compounds play an important role in all these domains [1-3, 15-18]. Many heterocycles are aromatic and possess a "flat" structure and they are easily synthesized by many coupling reactions. A particular interest is in access to tridimensional ring structures. [18-20] In this regard, stereoselectivity becomes an important topic. In the past, photochemical reactions were often considered as inherently unselective because the energy uptake in such transformations is high and the dispersion of the excitation energy can only occur without any control. In fact, the dispersion of this energy can be controlled [21] and selective, also stereoselective or stereospecific reactions are observed. In the literature numerous of such reactions are reported [22-30]. Often supramolecular structures in the broadest sense are frequently involved [31-35]. Recently in connection with different types of photocatalysis, the application of photochemical reactions to organic synthesis has gained enormous interest [36-39].

It should further be pointed out that organic photochemical reactions play a key role in the context of sustainable chemistry. This was recognized more than 100 years ago when comparing organic photochemical reactions to photosynthesis of green plants [40-42]. It is the beginning of 
"Green Chemistry" [43-45]. In fact, many of these reactions fulfill requirements of sustainable chemistry [46, 47].

Various methods of chemical engineering are developed for photochemical reactions. Micro-reactor systems are constructed to optimize these reactions with respect to problems in connection to optical density of the reaction mixtures and also to face safety problems. A continuous production is of general interest in chemical industry [48-53]. In this context, flow reactors are developed. It should also be pointed out that sunlight is an abundantly available light source free of charge. Optimized reactors have been constructed for solar photochemical transformations [54].

In the present article, methods will be presented which lead directly to enantiopure or enantioenriched compounds. Heteroatoms of the newly formed heterocycle may be involved as essential part of the chromophore or the reaction center. A large number of examples are reported in which the heteroatom acts as a linker in a side chain. The review is not comprehensive. Characteristic examples from different domains are discussed.

\section{Chiral induction with template structures}

The transformation of substrates which are complexed to enantiopure compounds leads to enantiopure or enantioenriched products [34]. This strategy was applied to the intramolecular addition of a tertiary amine to an $\alpha, \beta$-unsaturated lactam (Scheme 1) [55]. In this reaction, photochemical electron transfer plays a key role. The lactam $\mathbf{1}$ is complexed with a Kemp's acid derivative via hydrogen bonds (2). In this complex, the benzophenone derived sensitizer is placed close to the substrate. After excitation of the former, electron transfer occurs from the tertiary amine (pyrrolidine moiety) to the sensitizer leading to the radical ion pair $\mathbf{3}$. Transfer of a proton yields the neutral radical intermediates in structure 4. In a Michael type reaction, the nucleophilic $\alpha$-aminoalkyl radical adds to the lactam moiety. The resulting neutral intermediate $\mathbf{5}$ possesses an electrophilic oxoallyl radical and a nucleophilic ketyl radical. Electron transfer (6) followed by a proton transfer yields the spirocyclic final product 7 . In these radical addition and hydrogen atom transfer steps, polar effects play an important role [56-58]. In reactions like the ones discussed here, mainly two different mechanisms of the hydrogen atom transfer (HAT) are frequently discussed $[59,60]$. In the present case, a two-step process takes place. The electron transfer occurs first and the proton follows [61-64]. In cases, where the photochemical electron transfer is endergonic, the formation of neutral radicals however is exergonic, the HAT occurs in one step. In a more general context, such processes are discussed as proton coupled electron transfer (PCET) processes [65-67]. In the case of the reaction depicted in Scheme 1, hydrogen bonds are also involved which further favors such processes. The aromatic ketone in the Kemp's acid derivative acts not only as photochemical sensitizer but also as diastereo-differentiating shielding group.

Using the very similar template 10, an intramolecular $[2+2]$ photocycloaddition was carried out with the $\alpha, \beta$ unsaturated lactam derivative 8 (Scheme 2) [68]. In this
Scheme 1 Enantioselective cyclization involving photochemical electron transfer
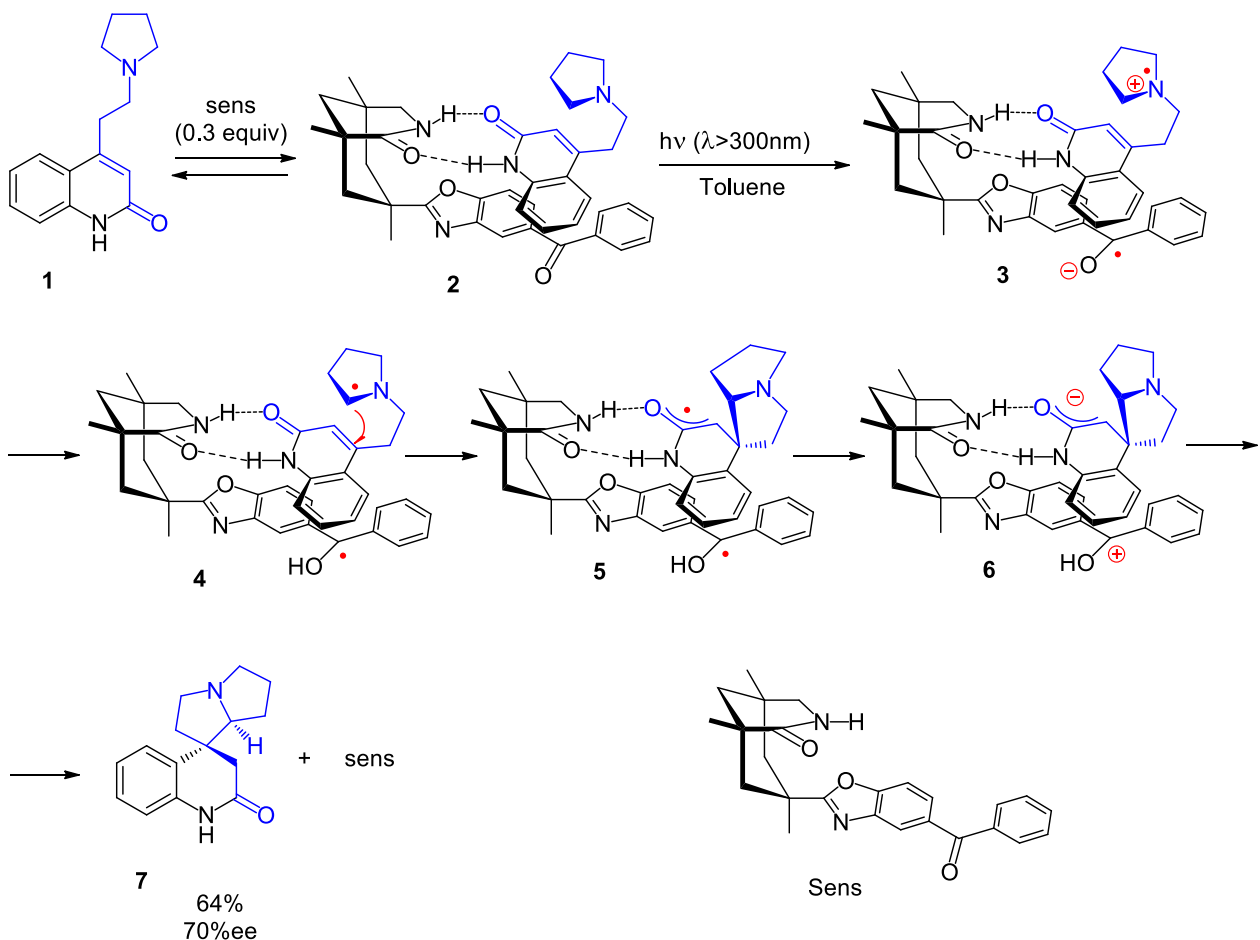

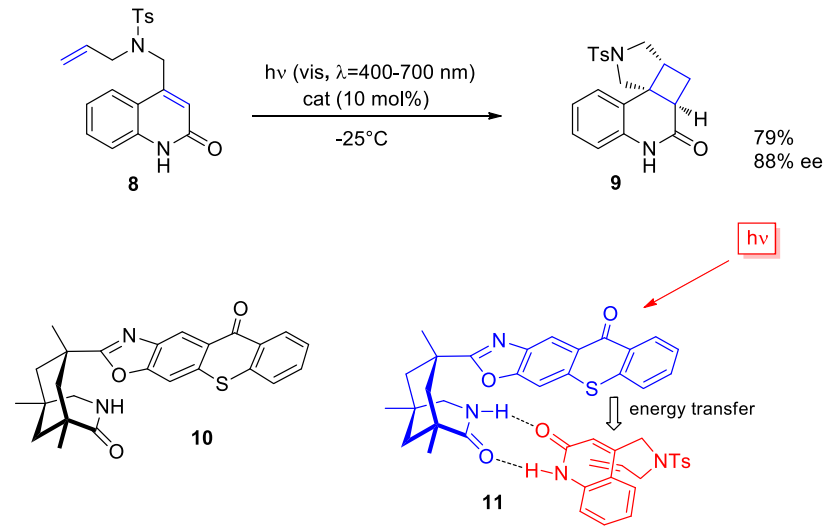

Scheme 2 Enantioselective synthesis of a polycyclic pyrrolidine derivative using a $[2+2]$ photocycloaddition

reaction the pyrrolidine derivative 9 was formed with a high enantioselectivity. The irradiation was performed with visible light. Under these conditions, the photocycloaddition can take place almost only in the template structure $\mathbf{1 1}$ where the thioxanthone group absorbs visible light (Fig. 1). The triplet energy of the sensitizer is transferred to the lactam which undergoes $[2+2]$ photocycloaddition at its $\mathrm{T}_{1}$ state. The non-complexed lactam undergoes the same reaction, when irradiated with UV light. As in the previous case, the sensitizer also acts as diastereo-differentiating shielding group. In a similar way, tetrahydrofuran derivatives can be synthesized [69-71].

Using almost the same reaction conditions as the transformation of the quinolinone derivative 8 (compare Scheme 2), the quinoxalinone derivative $\mathbf{1 2}$ was transformed into corresponding azetidine $\mathbf{1 3}$ was obtained in high yield and high enantioselectivity (Scheme 3) [72]. The reaction was also successfully carried out in an intermolecular way.

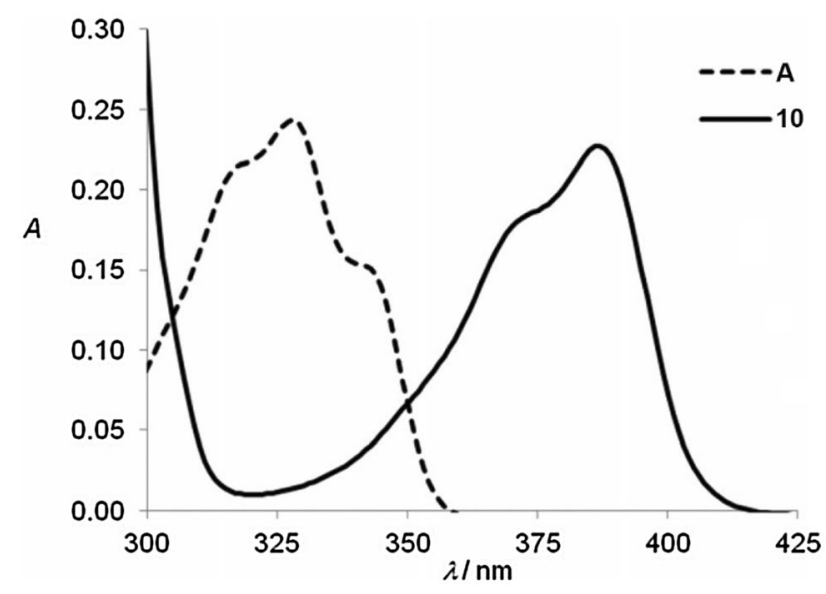

Fig. 1 UV/Vis spectra of a similar quinolin-2(1H)-one derivative A $(c=0.5 \mathrm{mM})$ and $\mathbf{1 0}(c=0.5 \mathrm{mM})$ in trifluoromethyl benzene

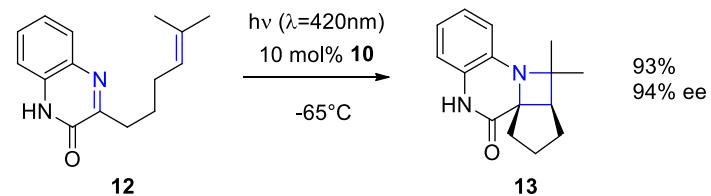

Scheme 3 Enantioselective intramolecular synthesis of an azetidine using the aza analogue Paternò-Büchi reaction

Complexation with Lewis acids often induces a bathochromic shift of a chromophore absorption. This property was applied to the enantioselective synthesis of polycyclic valerolactam derivatives such as $\mathbf{1 7}$. The complexation of dihydropyridinone derivative $\mathbf{1 4}$ with the chiral borane derivative 15 yields structure 16 (Scheme 4) [73]. The absorption of the chromophore is thus shifted to longer wavelengths (Fig. 2). When a corresponding reaction mixture is irradiated at $366 \mathrm{~nm}$, only the complex $\mathbf{1 6}$ is excited and chiral induction by the proline derived borate is efficient.

Chiral induction also occurs in the chiral ligand sphere of a metal. This strategy was applied to the transformation of benzaldehyde derivatives such as $\mathbf{1 8}$ into the tricyclic isochromanones 19 (Scheme 5) [74]. The substrate forms complexes 20 with enantiopure $\boldsymbol{\Delta}$-RhS. Complexation occurs via the carbonyl function of the $\alpha, \beta$ unsaturated carbonyl moiety and a pyrazole nitrogen atom. After photochemical excitation, intramolecular hydrogen atom transfer (HAT) occurs and the diradical intermediate $\mathbf{2 1}$ is generated [75]. A corresponding singlet species $\mathbf{2 2}$ is formed by an intersystem crossing step. In a rhodium catalyzed step, the cyclopropane complex $\mathbf{2 3}$ is formed. Ligand exchange yields the final product and enables complexation with the starting
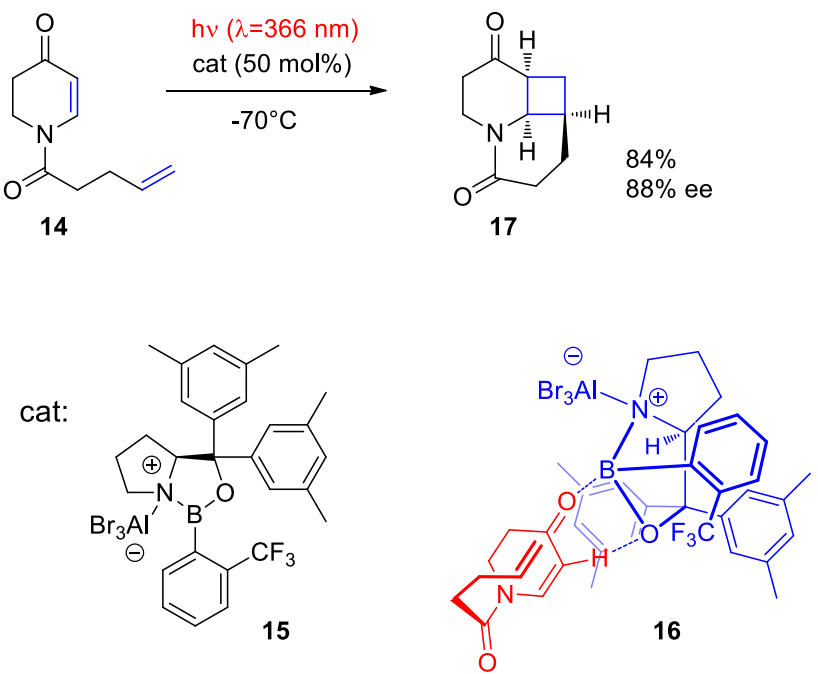

Scheme 4 Enantioselective acid catalyzed construction of a polycyclic valerolactam derivative via intramolecular $[2+2]$ photocycloaddition 
Fig. 2 Bathochromic shift of the absorption maximum of compound 14 by Lewis acid complexation. UV/vis spectra of $14\left(c=0.5 \mathrm{mM}\right.$ in $\left.\mathrm{CH}_{2} \mathrm{Cl}_{2}\right)$ in the absence and in the presence of 20 equivalents of a Lewis acid

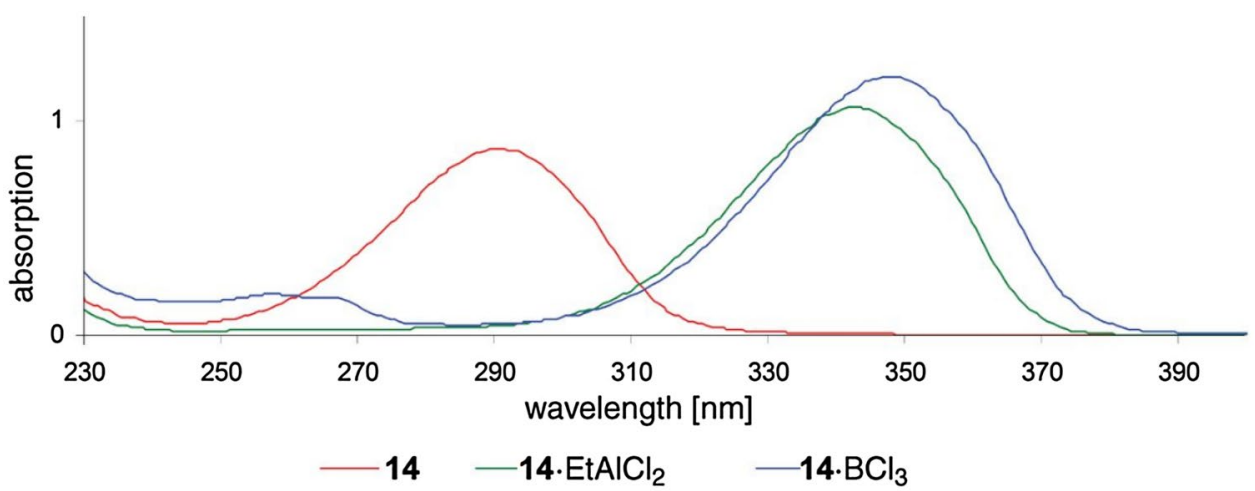

compound. The same strategy with a similar rhodium complex was applied to the synthesis of cyclic imines via $[2+3]$ photocycloaddition [76]. Complexation of a substrate to copper carrying a chiral bisdihydrooxazolylmethane ligand was used for the asymmetric synthesis of dihydrooxazole [77].

A large variety of TADDOLs $\left(\alpha, \alpha, \alpha^{\prime}, \alpha^{\prime}\right.$-tetraaryl-2,2disubstituted 1,3-dioxolane-4,5-dimethanol) can be synthesized from tartaric acid. They are capable of complexing numerous substrates via hydrogen bonds [78]. Such complexes are formed either in solution or in the solid state. When complexed with the TADDOL 31, the flavon derivative $\mathbf{2 4}$ undergoes photocycloaddition with the diphenylbutadiene $\mathbf{2 5}$ leading to compounds $\mathbf{2 6}$ and $\mathbf{2 7}$ (Scheme 6) [79]. After reduction the diastereoisomeric polycyclic compounds $\mathbf{2 8}$ and $\mathbf{2 9}$ are isolated. The major isomer 28 was obtained in high enantioselectivity. It has been suggested that a chromenylium structure is formed (30). This involves excited state intramolecular proton transfer (ESIPT) [80-82]. The alkene $\mathbf{2 5}$ reacts in a highly stereoselective $[2+3]$ cycloaddition. The reaction occurs at the triplet state and electron transfer may be involved. The enatiomeric purity was further increased by recrystallization. Compound 28 is an intermediate of the synthesis of (+)-foveoglin A.
Scheme 5 Asymmetric photocatalyzed synthesis of isochromanone compounds

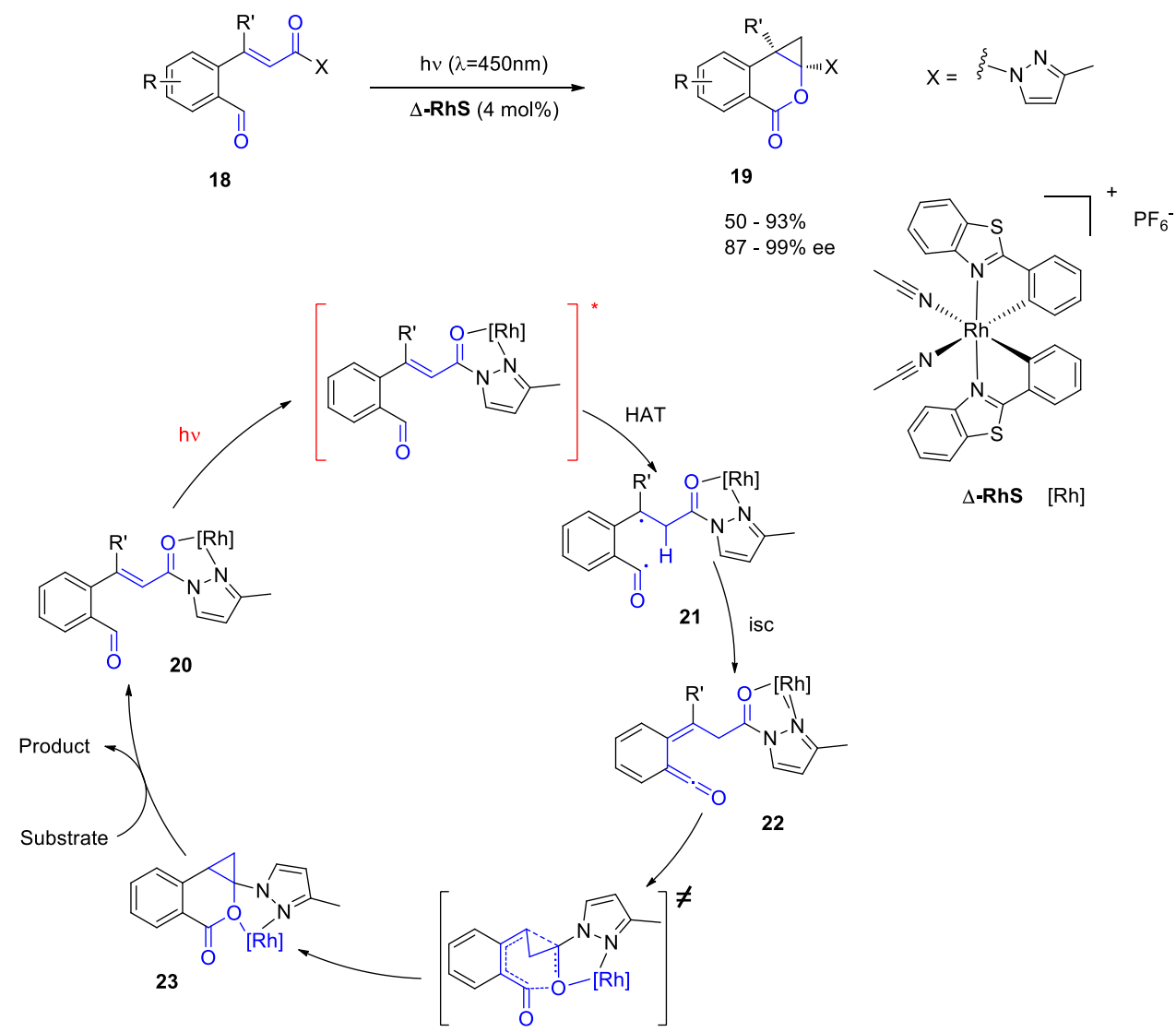




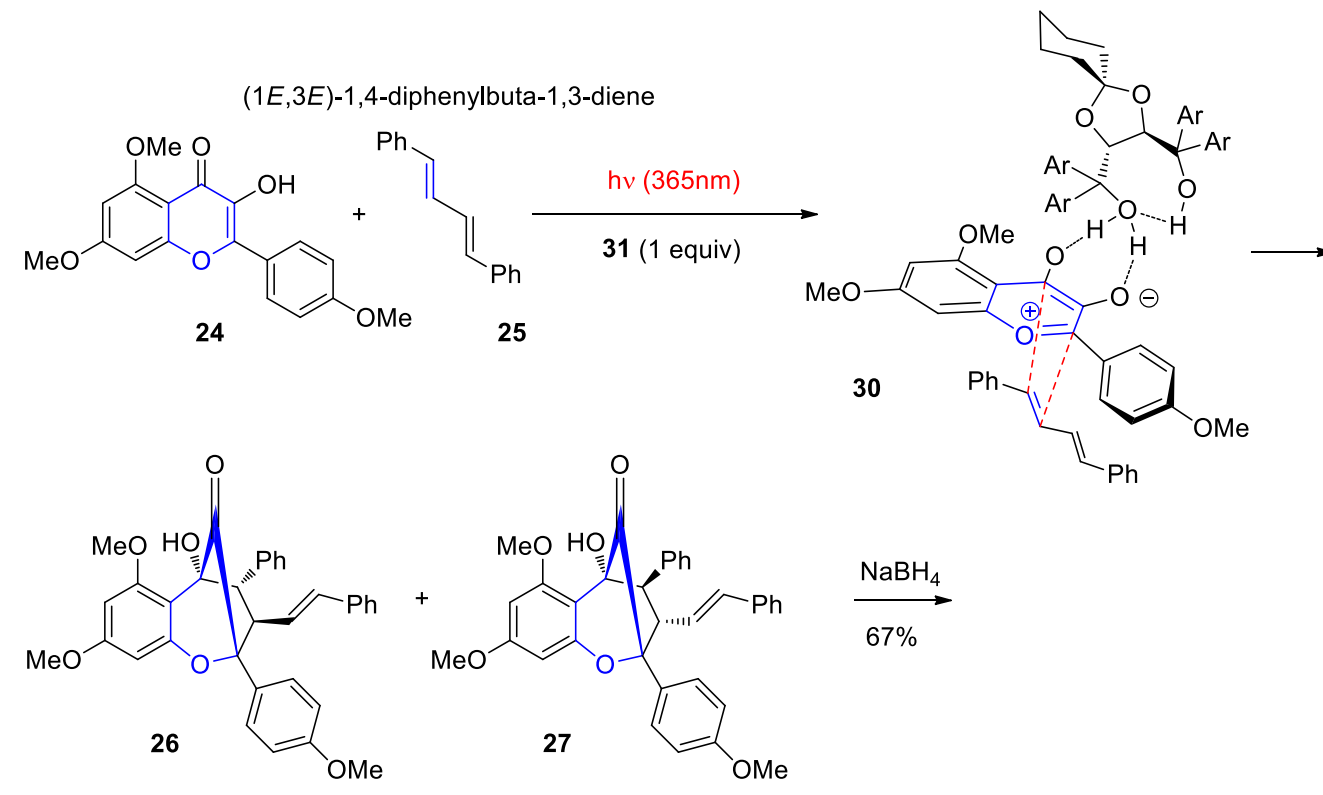

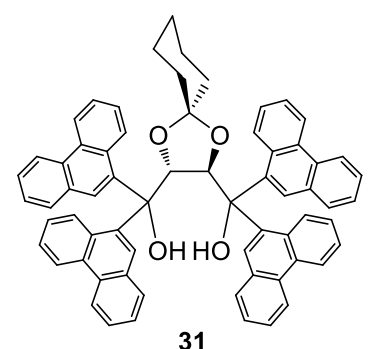

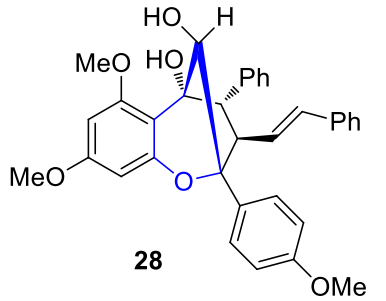

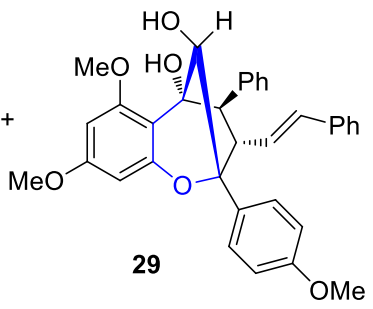

$83 \%$ ee $6: 1$ $93 \%$ ee (after recrystallisation)
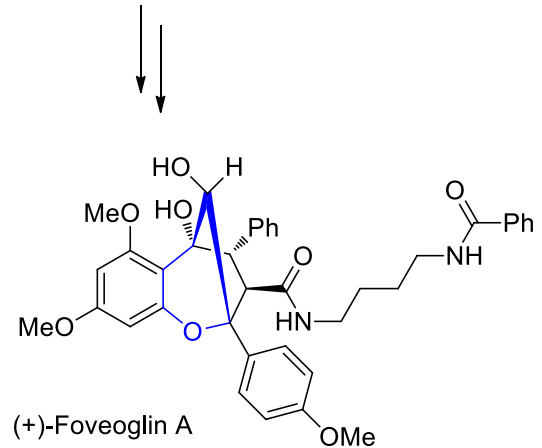

Scheme 6 Asymmetric synthesis of (+)-foveoglin A using ESIPT promoted [2+3] cycloaddition

The latter belongs to a compound family possessing anticancer and antiviral activities.

As already mentioned, proton coupled electron transfer (PCET) can be involved when substrates are complexed with templates via hydrogen bonds [65-67]. This interaction was used to efficiently induce chirality $[83,84]$. Thus the photocatalytically induced cyclization of sulfonamides $\mathbf{3 2}$ to the corresponding pyrrolidines $\mathbf{3 3}$ was carried out with high enantioselectivity (Scheme 7) [85]. The nitrogen centered radical species $\mathbf{3 4}$ is generated by electron transfer to the electronically excited iridium photocatalyst and a proton transfer to the chiral phosphate P1. Radical cyclization leads to the intermediate $\mathbf{3 5}$. In this step efficient chiral induction takes place. It occurs in close connection with $\mathbf{P 1}$.

Pyridines are important heterocycles and play a key role in many domains. The Vollhardt reaction provides an elegant access to these compounds. Two alkynes react with a nitrile derivative in a $[2+2+2]$ cycloaddition [86]. It has been shown that this reaction can be carried out under mild conditions with inexpensive cobalt catalysts 
Scheme 7 Enantioselective radical cyclization involving PCET

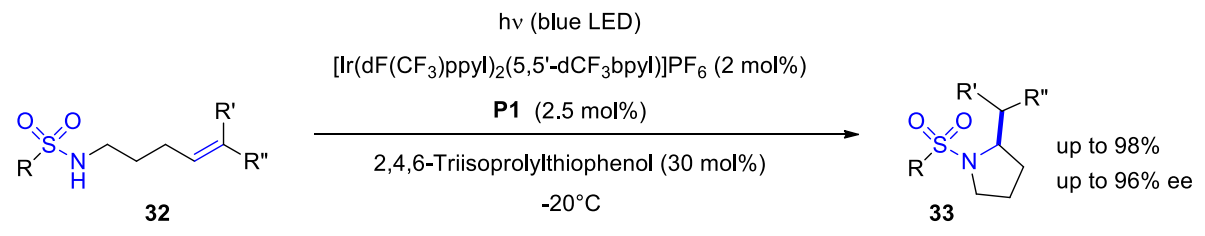

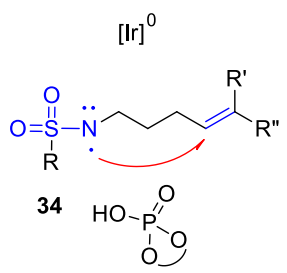

P1 0<smiles>[R]C([R])C1CCCN1S([R])(=O)=O</smiles>

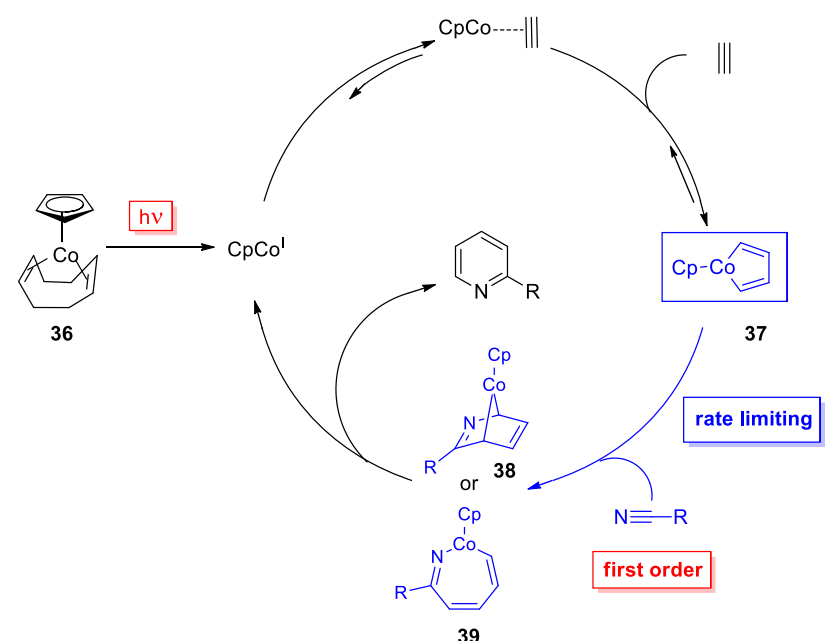

Scheme 8 Synthesis of pyridines with the cobalt catalyzed [2+2+2] cycloaddition. The reaction is performed under mild conditions using visible light irradiation

when the reaction solutions are irradiated with visible light (Scheme 8) [87, 88]. Under these conditions, the formation of the catalytically active species $\mathrm{CpCo}^{\mathrm{I}}$ from the precursor $\mathbf{3 6}$ is accelerated. It has been observed that the formation of the cobaltacyclopentadiene intermediate 37 is also accelerated since the formation of the intermediates 38 and $\mathbf{3 9}$ becomes the rate limiting. The overall reaction becomes first order concerning the consumption of the nitrile. A large number of pyridine derivatives has been obtained with this method $[89,90]$. Due to the mild reaction conditions, asymmetric catalysis with corresponding cobalt complexes was successfully performed. The chiral cobalt catalyst $\mathbf{4 0}$ was used to induce chirality in the reaction of the diine compound $\mathbf{4 1}$ with acetonitrile (Scheme 9) [91]. In this reaction, axial chirality in the pyridine compound $\mathbf{4 2}$ is induced. The enantiomers of $\mathbf{4 2}$ are also atropisomers. Under similar conditions, the cyanonaphthalene derivative $\mathbf{4 3}$ was transformed either with diines or with two equivalents of monoalkynes yielding tetracyclic (44) or tricyclic pyridines (45) respectively. In this context, it should be pointed out that atropisomerism in stereoselective photochemical reactions play an important role again [92].

\section{Photochemically supported enzymatic reactions}

Enzyme catalysis is an efficient method for the preparation of enantiomerically pure compounds [93]. Often multi enzyme systems are used for such transformations which complicates the application to organic synthesis. Photochemical transformations can simplify such transformations. Especially in the case of redox catalysis, photochemical reactions can replace one or more of enzyme activities in multi-enzyme systems. Mild photochemical conditions were applied to a large number of organic syntheses with enzymes [94-96].

The Baeyer-Villiger monooxygenase (BVMO) was efficiently applied to the asymmetric synthesis of lactones and esters (Scheme 10) [97-100]. Under normal conditions, the BVMO catalyzes the transformation of a ketone into an ester function (Scheme 10a). Molecular oxygen is used as oxidant which is first reduced to hydrogen peroxide by enzyme linked Flavin adenine dinucleotide $\left(E-F-D_{\text {red }}\right)$. The hydrogen peroxide undergoes the Baeyer-Villiger 
Scheme 9 Asymmetric catalysis of pyridines supported by irradiation with visible light
Scheme 10 a Baeyer-Villiger reaction under normal conditions using a two enzymesystem. b Replacement of the glucose dehydrogenase by a simple photoredox catalytic system based on non-linked FAD<smiles>C#CCCCCC#Cc1c(OC)ccc2ccccc12</smiles>

41

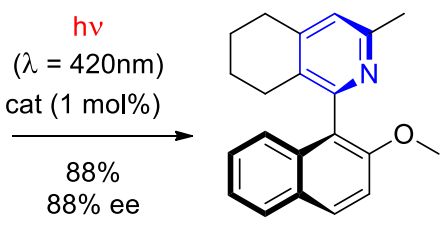

42 cat:

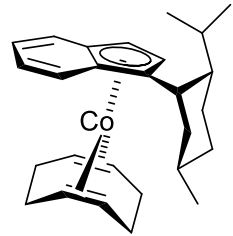

40<smiles>[R]c1ccc2ccccc2c1-c1nc([R])c2c(c1[R])CCC2</smiles>
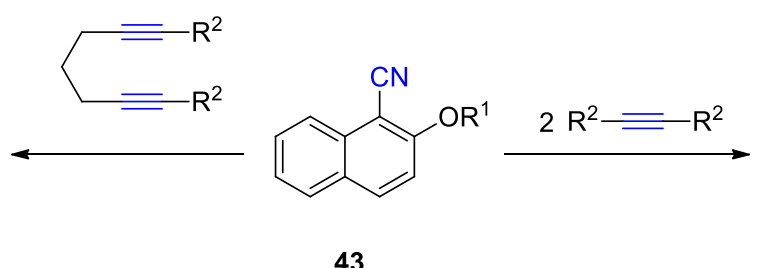

43<smiles>[R1]Oc1ccc2ccccc2c1-c1nc([R])c([R])c([R])c1[R]</smiles>

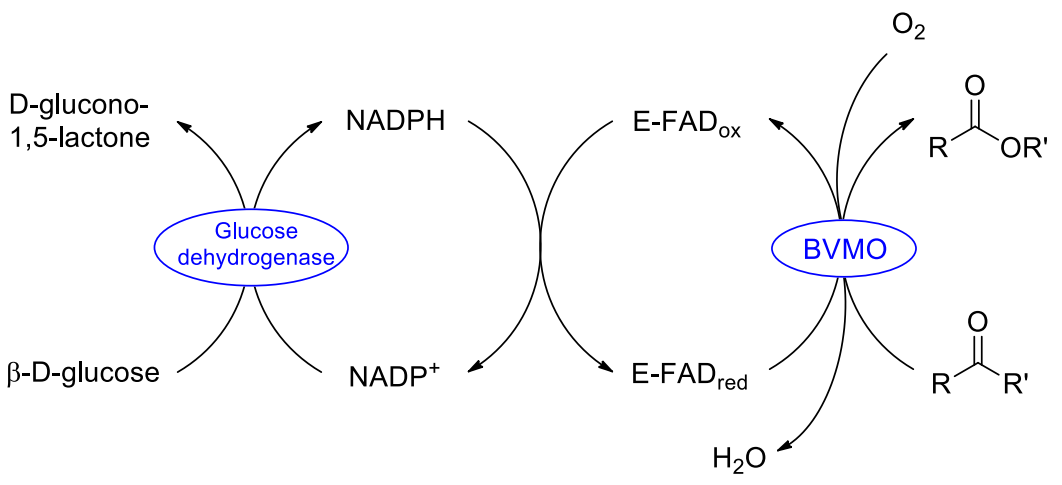

R: Adenine dinucleotide

E-FAD: Enzyme bound FAD

BVMO: Baeyer-Villiger monooxygenase

b

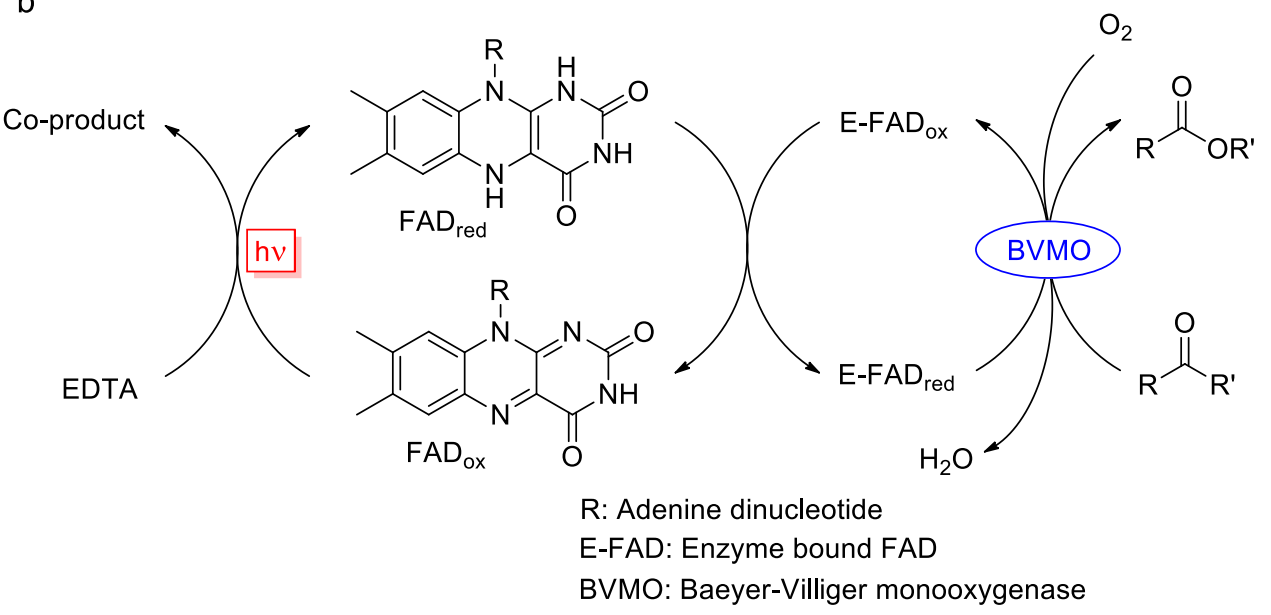

reaction with the ketone substrate. The oxidized flavin species is reduced by NADPH leading to E-FAD ${ }_{\text {red }}$ and $\mathrm{NADP}^{+}$. NADPH is regenerated by glucose dehydrogenase. This second enzyme activity was efficiently replaced by a simple photocatalytic reaction involving non linked
FAD (Scheme 10b). The enzyme-linked E-FAD ${ }_{\text {ox }}$ is reduced by free $\mathrm{FAD}_{\text {red }}$. The resulting $\mathrm{FAD}_{\mathrm{ox}}$ is reduced in a photoredox catalytic reaction using visible light irradiation. Various electron donors such as EDTA can be used for this step. 

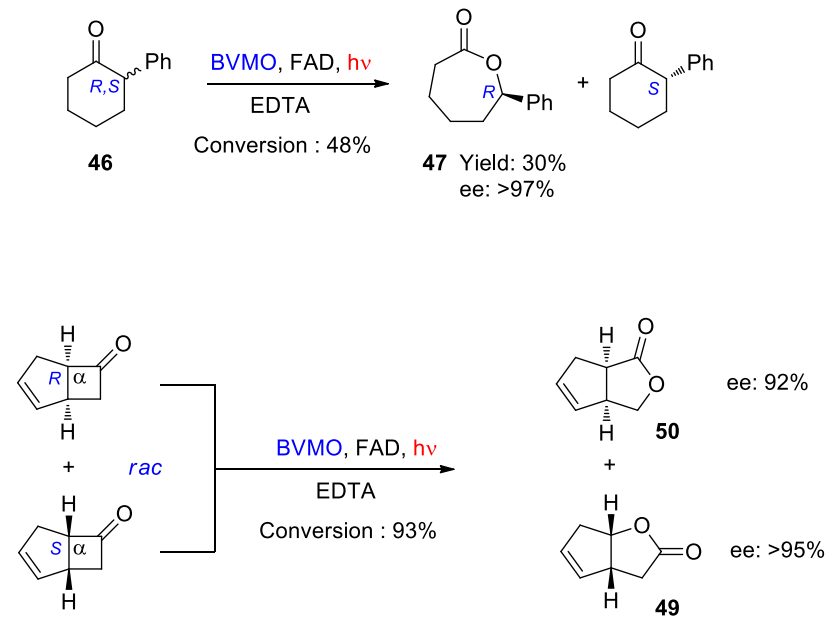

48

Scheme 11 Photochemically supported enzyme catalyzed BaeyerVilliger of a racemic ketones

Under these mild reaction conditions the racemic ketone 46 is partially transformed into the corresponding lactone (Scheme 11) [101]. Only the $R$ enantiomer of $\mathbf{4 6}$ is transformed and $\mathbf{4 7}$ is obtained in high enantio-purity. The $S$ enantiomer of $\mathbf{4 6}$ can also be isolated. In the case, of the bicyclic ketone 48 , both enantiomers are transformed. However, depending on the absolute configuration, two different regioisomers of the resulting lactones are formed in high enantioselectivity. The $\alpha-R$ enantiomer is transformed into the untypical $[102,103]$ Baeyer-Villiger product $\mathbf{5 0}$ while the reaction of the $\alpha-S$ enantiomer yields the bicyclic lactone 49.

Photoredox catalysis was also combined with alcohol dehydrogenase $(\mathrm{ADH})$ catalysis [104]. These enzymes use the $\mathrm{NAD}(\mathrm{P}) \mathrm{H} / \mathrm{NAD}(\mathrm{P})^{+}$system as cofactor [105]. The achiral diol 51 was enantioselectively oxidized to the lactol 52 by dehydrogenation of one alcohol function using horse liver alcohol dehydrogenase (HLADH) (Scheme 12) [106]. In this reaction step, one equivalent of $\mathrm{NADH}$ is formed. The corresponding $\mathrm{NAD}^{+}$form is regenerated in a photoredox catalytic reaction with flavin mononucleotide (FMN). In this step, molecular oxygen is used as electron acceptor yielding hydrogen peroxide. In a second reaction sequence, the lactol

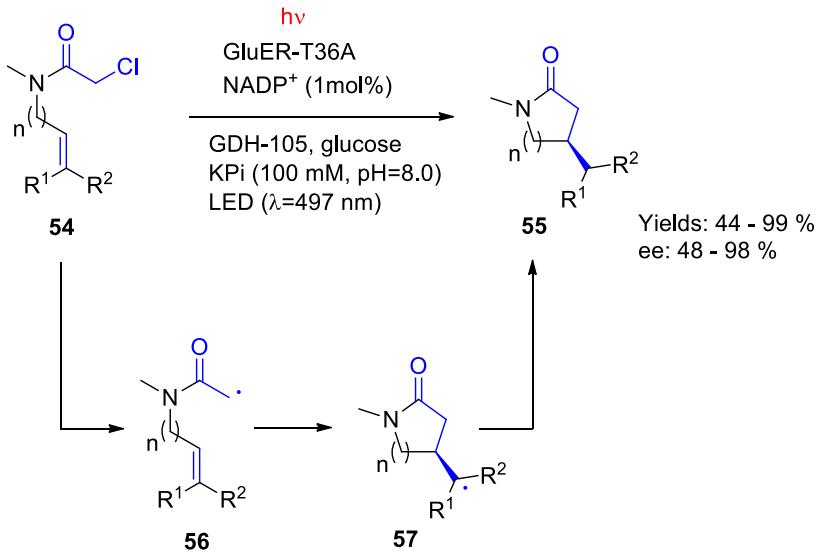

Scheme 13 Asymmetric radical cyclization induced by a photobiocatalytic step

$\mathbf{5 2}$ is transformed into the (S)-4-methylvalerolactone $\mathbf{5 3}$. The irradiation was carried out with blue LED $\left(\lambda_{\max }=465 \mathrm{~nm}\right)$.

Under similar reaction conditions using an ene-reductase, lactams have been enantioselectively synthesized (Scheme 13) [107]. $\alpha$-Halogenoacetamides such as $\mathbf{5 4}$ are transformed into lactams $\mathbf{5 5}$. In most cases, the products have been obtained in high yields with high enantioselectivities. An ene-reductase from Gluconobacter oxydans (GluER-T36A) was used which contains a flavin cofactor (FMN). The regeneration of NADP is catalyzed by a glucose dehydrogenase (GDH-105). The reactions starts with a photochemical electron transfer from the FMN of the enzyme to the substrate 54. It has been shown that the substrate $\mathbf{5 4}$ forms an electron donor acceptor complex with the reduced form of flavin compounds which is a precursor of the electron transfer. After release of chloride, the radical intermediate $\mathbf{5 6}$ is generated. Cyclization yields the intermediate 57. The final product $\mathbf{5 5}$ is obtained by hydrogen atom transfer (HAT). Very similar transformations have been carried out with anilides. In this case the $\alpha$-acyl radical adds to the aryl substituent which leads to oxindoles [108]. It should be mentioned that this reaction is a photocatalytic variant of the Witkop reaction [109].

The combination of enzymatic catalysis and photochemistry provides numerous perspectives for organic synthesis [110-113]. This strategy is also an important element of sustainable (green) chemistry. Enzymatic and

Scheme 12 Enantioselective synthesis of a lactone using photochemically supported enzyme catalysis
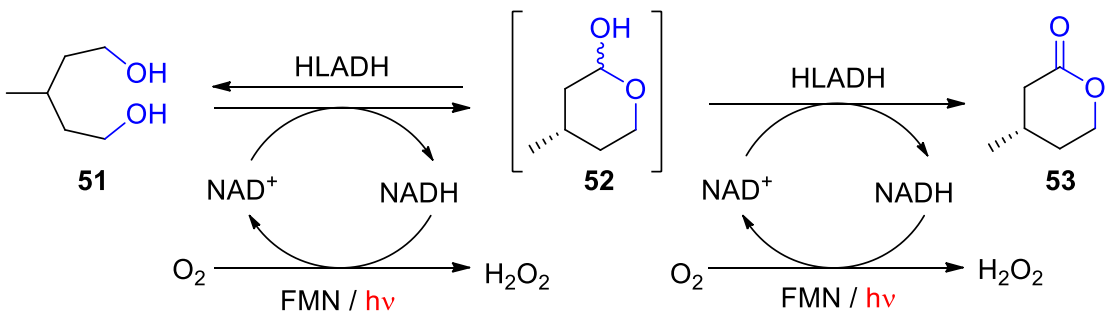

ee $>98 \%$ 
photochemical reactions are key processes of the photosynthesis of green plants. For this reason, they have already been considered as perspectives for a clean, nonpolluting chemical industry by G. Ciamician more than 100 years ago. [40-42] It is the beginning of green chemistry [43-45] although it has been forgotten over decades.

\section{Chiral induction in crystals}

Stereoselective synthesis is often linked to efficient conformation selection. The conformational rigidity in crystal is an efficient way to control conformational equilibria and to select a particular conformation. Packing in crystals may also orientate substrates in a particular way that is unfavorable in solution with the consequence to induce a particular photoreactivity. Molecular and crystal symmetry are connected [114]. Depending on the molecular symmetry, particular space groups are realized in crystal. Spectacular asymmetric reactions have been performed in crystals with achiral substrates which crystallize in Sohncke space groups $[115,116]$. Pure enantiomers can only crystalize in such symmetry groups. Achiral compounds may crystallize these groups. When they do so, most frequently, one enantiopure conformer is present in the homochiral crystals $[117,118]$. When chemical reactions are performed with such crystals, the products are most frequently formed in high enantiomeric excess. Such reactions are also discussed in the context of "absolute asymmetric synthesis" [119].

The $\alpha$-ketoamides $\mathbf{5 8}$ crystallize in Sohncke space groups and thus form enantiopure entities (Scheme 14) [120, 121]. Irradiation of such crystals leads to diradical intermediates 60. Radical combination yields enantio selectively the hydroxy- $\beta$-lactams $\mathbf{5 9}$. These reactions steps take place under strict conformation control by the crystal environment and high enantioselectivity is observed in most cases. For $\mathrm{Ar}=\mathrm{Ph}$, the substrate crystallized in the space group $\mathrm{P} 22_{1} 2_{1} 2_{1}$. 1122] Irradiation of corresponding homochiral crystals yields the corresponding photoproduct $\mathbf{5 9}(\mathrm{Ar}=\mathrm{Ph})$ with
Scheme 14 Enantioselective synthesis of $\beta$-lactams using absolute asymmetric synthesis with homochiral crystals<smiles>CC(C)N(C(=O)C(=O)[AlH2])C(C)C</smiles>

58<smiles>S=C(C1=CCCCC1)N(Cc1ccccc1)Cc1ccccc1</smiles>

61<smiles>CC(C)N(C(=O)C(O)[Al])C(C)C</smiles>

60

$54-100 \%$ ee

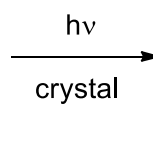<smiles>S=C1C(c2ccccc2)=CC2CCCCC12</smiles>

63

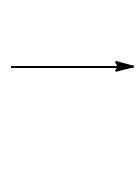<smiles>S=C1N(Cc2ccccc2)C(c2ccccc2)C12CCCCC2</smiles>

62

$81-97 \%$ ee

Scheme 15 Synthesis of $\beta$-lactams by photochemical transformation of chiral ammonium salts in the solid state
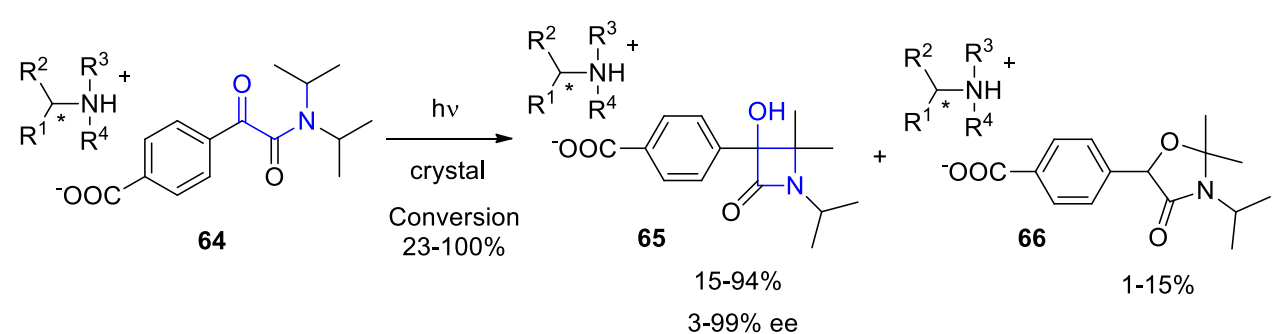

$3-99 \%$ ee
Scheme 16 Enantioselective photo-Claisen rearrangement in the solid state<smiles>O=C([O-])c1ccc(C(=O)C2C3C=CC2CC3)cc1</smiles>

67
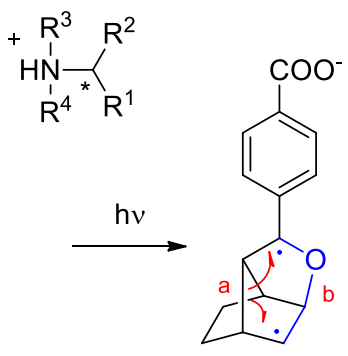

68

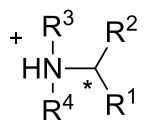<smiles>[R]C([R])C([R])[R]</smiles>

69 

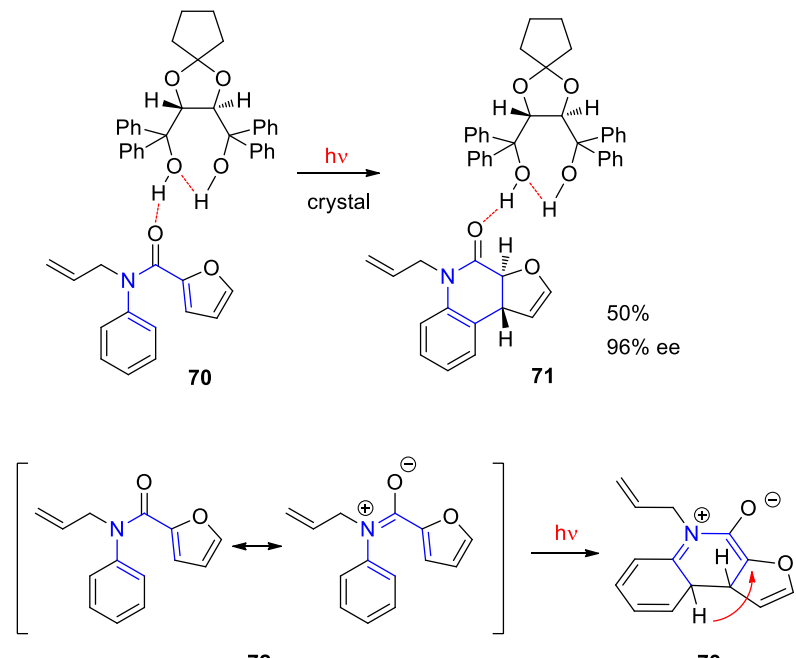

72

73

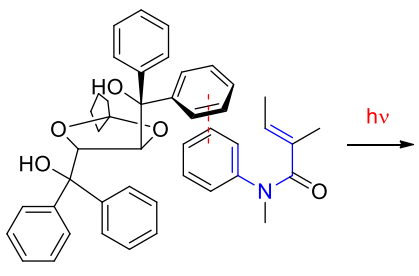

74

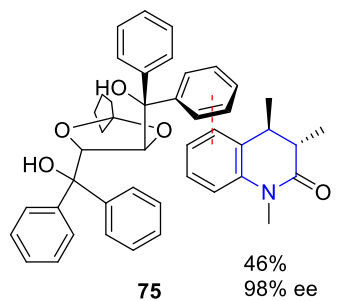

Scheme 17 Photochemical electrocyclization in TADDOL hostguest structures yielding quinolones in high enantioselectivity
93\% ee. The product crystalizes in the same space group $\mathrm{P} 2{ }_{1} 2_{1} 2_{1}$. In the present study, both enantiomers have been selectively prepared from the corresponding homochiral crystals. Under similar conditions the $\beta$-thiolactam 62 was enantioselectively prepared from the thioamide 61 [123]. The starting product $\mathbf{6 1}$ crystalizes in the space group $\mathrm{P} 2_{1}$. After photochemical excitation and intramolecular hydrogen atom transfer (HAT), the diradical intermediate $\mathbf{6 3}$ is formed. Radical combination yields the final product $\mathbf{6 2}$ in high enantioselectivity. When $\mathbf{6 1}$ is irradiated in solution the $\beta$-thiolactam $\mathbf{6 2}$ is formed as a racemate along with side products [124]. Further similar stereoselective reactions have been reported [125].

When particular crystallization methods, e.g. seeding crystallization with the desired homochiral crystal, the achiral starting compound can be selectively transformed into only one of the enantiomorphous crystals [126]. This method enables the controlled preparation of one desired enantiomer. It should further be pointed out that such solidstate photochemical reactions can also be carried out on larger scale when suspensions are irradiated [127]. This opens perspectives for an industrial production.

The combination of the photochemical substrate with a homochiral element also enables a control of the enantioselectivity. In this case, the compounds only crystalize in the 65 Sohncke space groups. A specific chiral environment is created around the substrate. [114-117] In the context of this topic, the chiral element is not covalently connected to the photochemical substrate [128]. In the case of ammonium
Fig. 3 X-ray structures of compound 70 (a) and 74 (b) in 1:1 cocrystals with a TADDOL (compare Scheme 17)
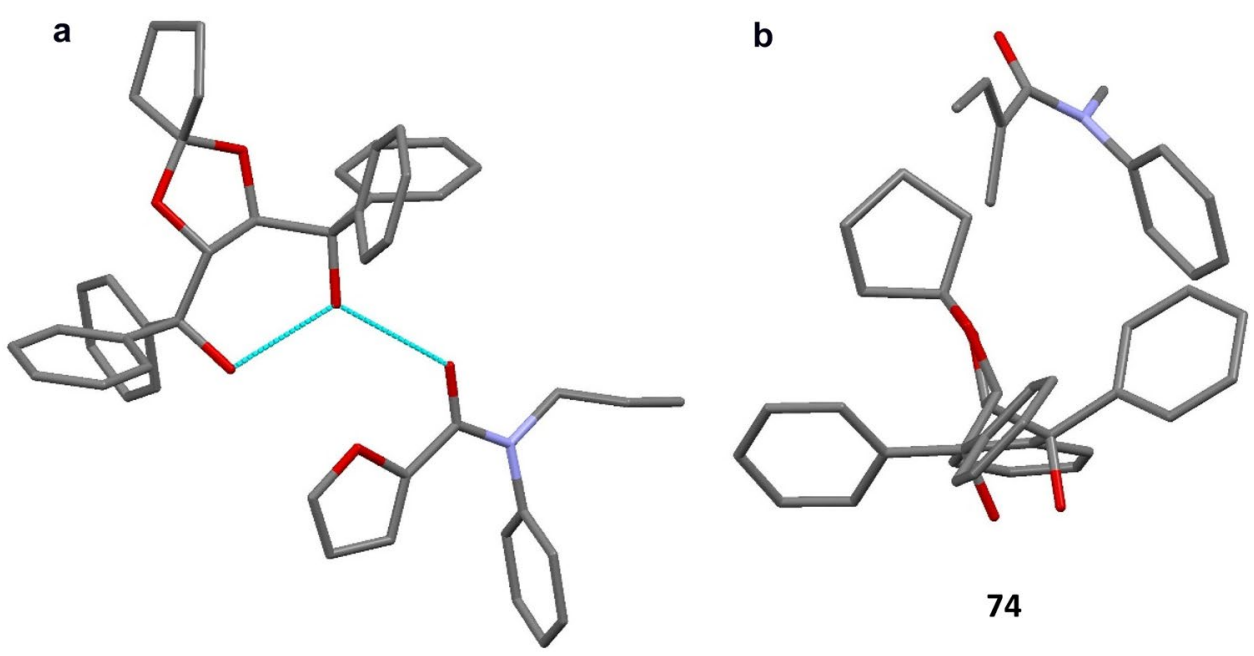

74

70

Scheme 18 Photochemical electrocyclization of the dihydroazepinone $\mathbf{7 6}$ complexed with $\beta$-cyclodextrin

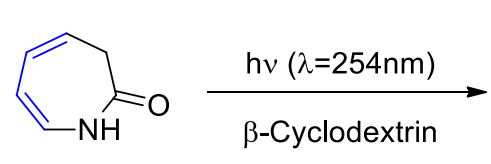

76<smiles>O=C1C[C@@H]2C=C[C@H]2N1</smiles>

77<smiles>O=C1CC(=O)N[C@@H]2CC[C@@H]2C1</smiles>

78
$75 \%$

$45 \%$ ee 


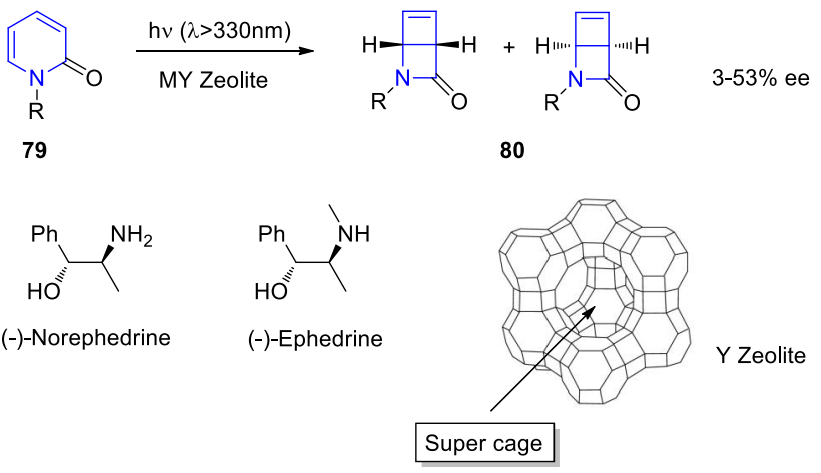

Scheme 19 Enantioselective photochemical electrocyclization of pyridones 79 yielding bicyclic $\beta$-lactams 80 . The pyridones are coabsorbed with chiral aminoalcohols in Y zeolites

salts of chiral amines such as 64 (Scheme 15), both elements are combined by ionic interactions [129]. Irradiation of such salts with an aromatic $\alpha$-ketoamide as chromophore in the solid state yields $\alpha$-hydroxy- $\beta$-lactams $\mathbf{6 5}$. In most cases, the products isolated as methyl benzoates (diazomethane workup) were obtained in high yield and enantioselectivity. Oxooxazolidines 66 were formed in minor amounts.

Under similar conditions the chiral ammonium salt of the norbornene derivative $\mathbf{6 7}$ undergoes an enantioselective photochemical Claisen rearrangement [130] leading to the bicyclic dihydrofuran compound 69 (Scheme 16) [131]. After photochemical excitation to the $n \pi^{*}$ state, the 1,4-diradical intermediate $\mathbf{6 8}$ is formed. Such intermediates are also formed in the Paternò-Büchi reaction [132-134] where they play a key role for the stereoselectivity [21, 135]. A typical reaction of such intermediates is the cleavage of the $\mathrm{C}-\mathrm{O}$ bond (b) regenerating the substrate which diminishes the quantum yield of such reactions. In the present case, a $\mathrm{C}-\mathrm{C}$ bond (a) of the norbornene fragment is cleaved yielding the final product 69. As in the previous case, the products were isolated as methyl benzoates (diazomethane workup).

\section{Inclusion structures}

It has already been pointed out that TADDOLs $\left(\alpha, \alpha, \alpha^{\prime}, \alpha^{\prime}-\right.$ tetraaryl-2,2-disubstituted 1,3-dioxolane-4,5-dimethanol) are efficient chiral auxiliaries that are not covalently bound to a reacting molecule. [78] These compounds are able to co-crystallize with numerous organic compounds. In these chiral host structures, the substrates react with high enantioselectivity [136-138]. Furoic acid amides easily co-crystallize with TADDOL (70) forming a 1:1 inclusion complex (Scheme 17) [139]. The interactions between host and guest are essentially established by hydrogen bonds (Fig. 3a). Due to the polar mesomeric structure $\mathbf{7 2}$, irradiation of such crystals leads to a conrotatory electrocyclic reaction of the $6 \pi$ system with formation of intermediate 73. Tautomerization yield the final product $\mathbf{7 1}$ in high enantioselectivity. Under similar conditions, the same reaction has been carried out with the acrylanilide 74. In a 1:1 crystalline inclusion complex, the interactions between the host and guest structures are essentially based on van der Waals $\pi \pi$-stacking or edgeto-face bonds (Fig. 3b) [140]. Irradiation of the inclusion complex again leads to the quinolone derivative $\mathbf{7 5}$ in high enantioselectivity.

Cyclodextrins are frequently studied as host structure for inclusion complexes [35, 141-143]. The unsaturated lactam 76 forms an inclusion complex with $\beta$-cyclodextrin (Scheme 18) [144]. The 1:1 complex is obtained as a water insoluble powder. A corresponding suspension was irradiated with UV light. Under these conditions, a disrotatoric electrocyclic reaction takes place leading to the bicyclic butyrolactam 77. Hydrogenation yields the corresponding cyclobutane derivative $\mathbf{7 8}$ in good yield and moderate enantioselectivity.

Zeolites are porous aluminosilicates which absorb organic molecules of different sizes depending on the dimensions of the cavities [145-147]. They are used as catalysts in many domains of chemistry, also in chemical industry. Zeolites have also been used as host structure for photochemical reactions [148-150]. The photochemical electrocyclization of pyridone derivatives such as $\mathbf{7 9}$ have been performed in super cages of MY zeolites (Scheme 19) [151]. M are different alkali metals. These cages are achiral. In order to induce enantioselectivity in a chiral environment, (-)-norephedrine or (-)-ephedrine were adsorbed together with the substrate 79. A maximum of interaction with the chiral inductor was established by using a tenfold excess for the preparation of the host guest structure. Although not covalently bound and due to the confinement in the super cages, the pyridone substrate is placed close to the enantiopure aminoalcohol and a control of the conformer equilibrium becomes possible. The presence of larger substituents $\mathrm{R}$ on the pyridone leads to higher enantiomeric excesses (up to 53\%) in the bicyclic $\beta$-lactams 80. It should be pointed out that when the reaction was carried out in solution and in the presence of dissolved chiral aminoalcohols, no chiral induction was detected. When the pyridone carries a covalently bonded chiral auxiliary, the diastereo-selectivity is improved when the reaction is carried out in zeolites instead of solution.

\section{Memory of chirality}

In many stereoselective reactions, the chiral information is transferred from a center of chirality, for example an asymmetric carbon atom, to the reaction center [152]. The products are obtained with a certain diastereo-selectivity. In particular cases, the initial chiral information is destroyed 
Scheme 20 Memory of chirality with inversion of configuration in a photochemical decarboxylation cyclization reaction (above). Memory of chirality with retention of configuration in an electrochemical reaction (bottom)
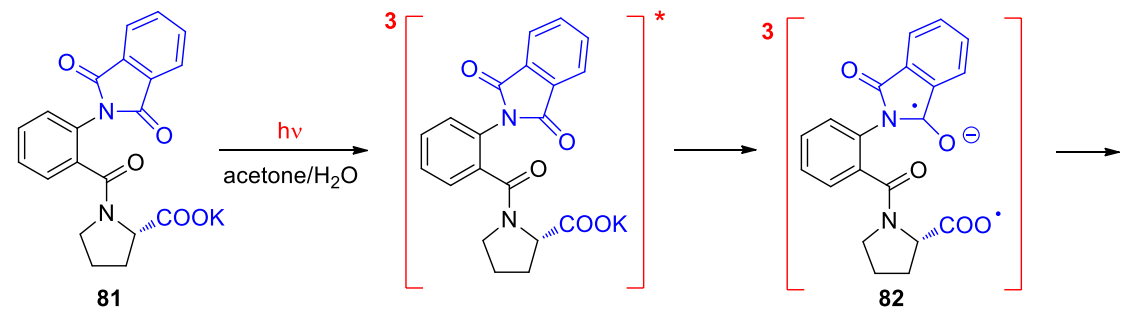

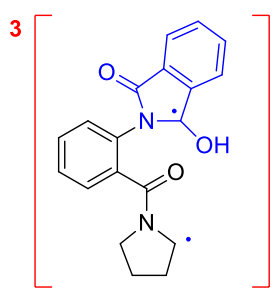

83

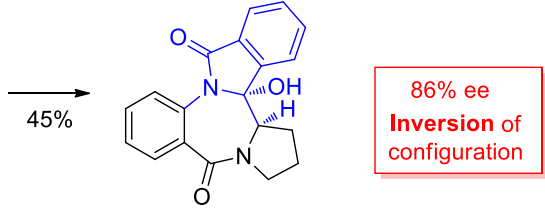

84
3

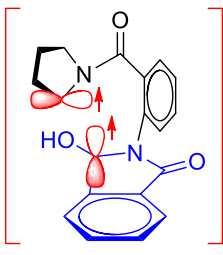

85
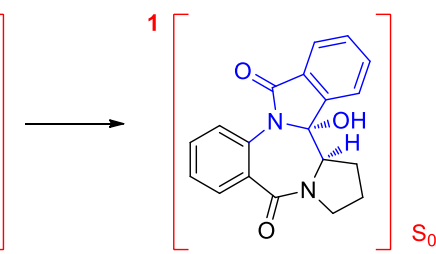

86

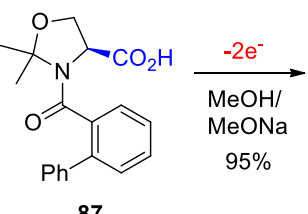

87<smiles>CO[C@H]1COC(C)(C)N1C(=O)c1ccccc1-c1ccccc1</smiles>

88
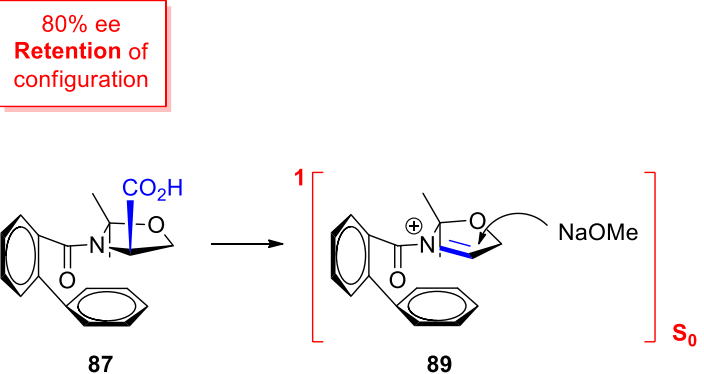

during the reaction and before the final products are formed. The chiral information is then conserved in more or less stable conformers or non-covalent interactions and the reactions remain stereoselective. This phenomenon is called "memory of chirality" [153-156].

The proline derivative $\mathbf{8 1}$ was irradiated in an acetone/ water mixture (Scheme 20) [157]. Under these conditions acetone is electronically excited and transfers its triplet energy to 81. Intramolecular electron transfer from the carboxylate function to the phthalimide moiety yields the intermediate 82. Immediate decarboxylation leads to the $\alpha$-aminoalkyl radical species $\mathbf{8 3}$. In this step, the chiral information initially localized in an asymmetric carbon atom is lost. Radical cyclization yields the final product 84 in high enantioselectivity. It must be pointed out that the chiral information that is intermediately conserved in a conformationally rigid structure is transferred by inversion of configuration. This observation is explained by the fact that the spin multiplicity changes from the triplet in the diradical intermediate $\mathbf{8 3}, \mathbf{8 5}$ to the singlet state in the final product 86. In such a process, intersystem crossing and radical combination concomitantly occurs when both radical carrying p orbitals are orthogonally orientated as depicted in structure 85 [158-160]. Such an arrangement increases spin orbit coupling. Among numerous conformations in such a structure that one of a minimum of steric hindrance is privileged which has a significant impact on the stereoselectivity of these reactions $[161,162]$. It was shown for a similar electrochemical reaction that compound $\mathbf{8 7}$ was transformed into compound $\mathbf{8 8}$ with almost the same enantioselectivity but with retention of configuration [156, 163, 164]. This result was explained by the fact that the reaction step in which the center of chirality is created (89) takes place exclusively at the singlet state. Further examples of memory of chirality 
effects have been reported for photochemical reactions involving radical intermediates [165-169].

\section{Conclusion}

Synthesis strategies giving systematic access to enantiopure heterocyclic compounds are appreciated and also provide perspectives for chemical industry. These compounds are needed in many domains such as new biologically active compounds for medicine and agriculture or for material science. As organic photochemical reactions in general, such transformation are also of high interest in the context of sustainable chemistry.

Templates or organometallic compounds currently play an important role when photoredox catalytic or photosensitized reactions are studied. [34, 36-39] Enzyme catalysis is an important tool in asymmetric synthesis. Using photochemical conditions and reactions can simplify and improve such reactions. [94-96] For example, co-catalytic steps may be replaced by simple photochemical reactions. Performing photochemical reactions in the crystalline state [117] is an efficient method for the enantioselective synthesis of heterocyclic compounds. It is certainly the most efficient method to freeze conformers and thus control the stereoselectivity. This provides also interesting perspectives for material science. Supramolecular structures, such as inclusion complexes provide numerous methods for enantioselective photochemical reactions [31-33, 170, 171]. With such reactions, many fundamental aspects of chemical reactivity can be studied. For example, the influence of the intersystem crossing on the stereoselectivity was studied in connection with memory of chirality effects.

Acknowledgements We are grateful for current funding of our research by the ANR (Agence nationale de la recherche, projects: IMPHOCHEM, NoPerox), the Communauté Urbaine du Grand Reims and the Université de Reims Champagne-Ardenne.

\section{Declarations}

Conflict of interest The author states that there is no conflict of interest.

\section{References}

1. Hoffmann, N. (2008). Photochemical reactions as key steps in organic synthesis. Chemical Reviews, 108, 1052-1103.

2. Bach, T., \& Hehn, J. P. (2011). Photochemical reactions as key steps in natural product synthesis. Angewandte Chemie International Edition, 50, 1000-1052.
3. Kärkäs, M. D., Porco, J. A., \& Stephenson, C. R. J. (2016). Photochemical approaches to complex chemotypes: Application in natural product synthesis. Chemical Reviews, 116, 9683-9747.

4. Gerry, C. J., \& Schreiber, S. L. (2018). Chemical probes and drug leads from advances in synthetic planning and methodology. Nature Reviews, 17, 333-352.

5. Schreiber, S. L. (2000). Target-oriented and diversity-oriented organic synthesis in drug discovery. Science, 287, 1964-1969.

6. Galloway, W. R. J. D., Isidro-Llobet, A., \& Spring, D. R. (2010). Diversity-oriented synthesis as a tool for the discovery of novel biologically active small molecules. Nature Communications, 1 , 80.

7. Beletskaya, I. P., Nájera, C., \& Yus, M. (2020). Chemodivergent reactions. Chemical Society Reviews, 49, 7101-7166.

8. Turro, N. J., \& Schuster, G. (1975). Photochemical reactions as a tool in organic synthesis. Science, 187, 303-312.

9. Klan, P., \& Wirz, J. (2009). Photochemistry of organic compounds. Wiley.

10. Buzzetti, L., Crisenza, G. E. M., \& Melchiorre, P. (2019). Mechanistic studies in photocatalysis. Angewandte Chemie International Edition, 58, 3730-3747.

11. Dinges, J., \& Lamberth, C. (Eds.). (2012). Bioactive heterocyclic compound classes-Pharmaceuticals. Wiley-VCH.

12. Lamberth, C., \& Dinges, J. (Eds.). (2012). Bioactive heterocyclic compound classes-Agrochemicals. Wiley-VCH.

13. Krämer, W., Schirmer, U., Jeschke, P., \& Witschel, M. (Eds.). (2012). Modern crop protection compounds, Vol. 1-3 (2nd ed.). Wiley-VCH.

14. Ostroverkhova, O. (Ed.). (2019). Handbook of organic materials for electronic and photonic devices (2nd ed.). Elsevier.

15. Lefebvre, C., Fortier, L., \& Hoffmann, N. (2020). Photochemical rearrangements in heterocyclic chemistry. European Journal of Organic Chemistry, 2020, 1393-1404.

16. Latrache, M., \& Hoffmann, N. (2021). Photochemical radical cyclization reactions with imines, hydrazones, oximes and related compounds. Chemical Society Reviews, 50, 7418-7435.

17. Taylor, R. D., MacCoss, M., \& Lawson, A. D. G. (2014). Rings in drugs. Journal of Medicinal Chemistry, 57, 5845-5859.

18. Aldeghi, M., Malhotra, S., Selwood, D. L., \& Cahn, A. W. E. (2014). Two and three-dimensional rings in drugs. Chemical Biology \& Drug Design, 83, 450-461.

19. Lovering, F., Bikker, J., \& Humblet, C. (2009). Escape from flatland: Increasing saturation as an approach to improving clinical success. Journal of Medicinal Chemistry, 52, 6752-6756.

20. Stockdale, T. P., \& Williams, C. M. (2015). Pharmaceuticals that contain polycyclic hydrocarbon scaffolds. Chemical Society Reviews, 44, 7737-7763.

21. Oelgemöller, M., \& Hoffmann, N. (2016). Studies in organic and physical photochemistry-An interdisciplinary approach. Organic \& Biomolecular Chemistry, 14, 7392-7442.

22. Roth, H. D. (1989). The beginnings of organic photochemistry. Angewandte Chemie International Edition, 28, 1193-1207.

23. Rau, H. (1983). Asymmetric photochemistry in solution. Chemical Reviews, 83, 535-547.

24. Inoue, Y. (1992). Asymmetric photochemical reactions in solution. Chemical Reviews, 92, 741-770.

25. Inoue, Y., \& Ramamurthy, V. (Eds.). (2004). Chiral photochemistry. Marcel Dekker.

26. Griesbeck, A. G., \& Meierhenrich, U. (2002). Asymmetric photochemistry and photochirogenesis. Angewandte Chemie International Edition, 41, 3147-3154.

27. Meggers, E. (2015). Asymmetric catalysis activated by visible light. Chemical Communications, 51, 3290-3301.

28. Prentice, C., Morrisson, J., Smith, A. D., \& Zysman-Colman, E. (2020). Recent developments in enantioselective photocatalysis. Beilstein Journal of Organic Chemistry, 16, 2363-2441. 
29. Rigotti, T., \& Alemán, J. (2020). Visible light photocatalysisFrom racemic to asymmetric activation strategies. Chemical Communications, 56, 11169-11190.

30. Genzink, M. J., Kidd, J. B., Swords, W. B., \& Yoon, T. P. (2021). Chiral photocatalysts structures in asymmetric photochemical synthesis. Chemical Reviews. https://doi.org/10.1021/acs.chemr ev.1c00467

31. Ramamurthy, V., \& Sivaguru, J. (2016). Supramolecular photochemistry as a potential synthetic tool: Photocycloaddition. Chemical Reviews, 116, 9914-9993.

32. Ramamurthy, V., \& Mondal, B. (2015). Supramolecular photochemistry concepts highlighted with select examples. Journal of Photochemistry and Photobiology C: Photochemistry Reviews, $23,68-102$

33. Vallavoju, N., \& Sivaguru, S. (2014). Supramolecular photocatalysis: Combining confinement and non-covalent interactions to control light initiated reactions. Chemical Society Reviews, 43, 4084-4101.

34. Brimioulle, R., Lenhart, D., Maturi, M. M., \& Bach, T. (2015). Enantioselective catalysis of photochemical reactions. Angewandte Chemie International Edition, 54, 3872-3890.

35. Yang, C., \& Inoue, Y. (2014). Supramolecular photochirogenesis. Chemical Society Reviews, 43, 4123-4123.

36. Stephenson, C. R. J., Yoon, T. P., \& MacMillan, D. W. C. (Eds.). (2018). Visible light photocatalysis in organic chemistry. Wiley VCH.

37. König, B. (Ed.). (2020). Photocatalysis (2nd ed.). Walter d Gruyter.

38. Michelin, C., \& Hoffmann, N. (2018). Photosensitization and photocatalysis-Perspectives in organic synthesis. ACS Catalysis, 8, 12046-12055.

39. Michelin, C., \& Hoffmann, N. (2018). Photocatalysis applied to organic synthesis-A green chemistry approach. Current Research in Green and Sustainable Chemistry, 10, 40-45.

40. Ciamician, G. (1912). The Photochemistry of the Future. Science, 36, 385-394.

41. Ciamician, G. (1908). Sur les actions de la lumière. Bulletin de la Société Chimique de France, 3, i-xxvii.

42. Paternò, E. (1909). I nuovi orizzonti della sintesi in chimica organica. Gazzetta Chimica Italiana, 39, 213-219.

43. Albini, A., \& Fagnoni, M. (2008). 1908 Giacomo Ciamician and the concept of green chemistry. Chemsuschem, 1, 63-66.

44. Albini, A., \& Fagnoni, M. (2004). Green chemistry and photochemistry were born at the same time. Green Chemistry, 6, $1-6$.

45. Albini, A., \& Dichiarante, V. (2009). The "Belle époque" of photochemistry. Photochemical \& Photobiological Sciences, 8 , 248-254.

46. Anastas, P. T., \& Kirchhoff, M. M. (2002). Origins, current status, and future challenges of green chemistry. Accounts of Chemical Research, 35, 686-694.

47. Protti,S., Manzini, S., Fagnoni, M., \& Albini, A. (2009). The contribution of photochemisty to green chemistry. In R. Ballini (Ed.), RSC green chemistry book series, eco-friendly synthesis of fine chemicals (pp. 80-111). Royal Society of Chemistry.

48. Loubière, K., Oelgemöller, M., Aillet, T., Dechy-Cabaret, O., \& Prat, L. (2016). Continuous-flow photochemistry: A need for chemical engineering. Chemical Engineering and Processing, 104, 120-132.

49. Cambié, D., Bottecchia, C., Straathof, N. J. W., Hessel, V., \& Noël, T. (2016). Application of continuous-flow photochemistry in organic synthesis, material science, and water treatment. Chemical Reviews, 116, 10276-10341.

50. Mizuno, K., Nishiyama, Y., Ogaki, T., Terao, K., Ikeda, H., \& Kakiuchi, K. (2016). Utilization of microflow reactors to carry out synthetically useful organic photochemical reactions. Journal of Photochemistry and Photobiology C: Photochemistry Reviews, 29, 107-147.

51. Oelgemöller, M., Hoffmann, N., \& Shvydkiv, O. (2014). From 'lab \& light on a chip' to parallel microflow photochemistry. Australian Journal of Chemistry, 67, 337-342.

52. Knowles, J. P., Elliott, L. D., \& Booker-Milburn, K. I. (2012). Flow photochemistry: Old light through new windows. Beilstein Journal of Organic Chemistry, 8, 2025-2052.

53. Oelgemöller, M., \& Shvydkiv, O. (2011). Recent advances in microflow photochemistry. Molecules, 16, 7522-7550.

54. Oelgemöller, M. (2016). Solar photochemical synthesis: From the beginnings of organic photochemistry to the solar manufacturing of commodity chemicals. Chemical Reviews, 116, 9664-9682.

55. Bauer, A., Westkämper, F., Grimme, S., \& Bach, T. (2005). Catalytic enantioselective reactions driven by photoinduced electron transfer. Nature, 436, 1139-1140.

56. Fischer, H., \& Radom, L. (2001). Factors controlling the addition of carbon-centered radicals to alkenes - an experimental and theoretical perspective. Angewandte Chemie International Edition, 40, 1340-1371.

57. Roberts, B. P. (1999). Polarity-reversal catalysis of hydrogenatom abstraction reactions: Concepts and applications in organic chemistry. Chemical Society Reviews, 28, 25-35.

58. Ravelli, D., Fagnoni, M., Fukuyama, T., Nishikawa, T., \& Ryu, I. (2018). Site-selective C-H functionalization by Decatungstate anion photocatalysis: Synergistic control by polar and steric effects. ACS Catalysis, 8, 701-713.

59. Hoffmann, N. (2015). Electron and hydrogen transfer in organic photochemical reactions. Journal of Physical Organic Chemistry, 28, 121-136.

60. Hoffmann, N. (2016). Photochemical electron and hydrogen transfer in organic synthesis: The control of selectivity. Synthesis, 48, 1782-1802.

61. Bertrand, S., Hoffmann, N., Humbel, S., \& Pete, J.-P. (2000). Diastereoselective tandem addition-cyclization reactions of unsaturated tertiary amines initiated by photochemical electron transfer (PET). Journal of Organic Chemistry, 65, 8690-8703.

62. Hoffmann, N., \& Görner, H. (2004). Photoinduced electron transfer from $N$-methylpyrrolidine to ketones and radical addition to an electron-deficient alkene. Chemical Physics Letters, 383, 451-455.

63. Hoffmann, N., Bertrand, S., Marinković, S., \& Pesch, J. (2006). Efficient radical addition of tertiary amines to alkenes using photochemical electron transfer. Pure and Applied Chemistry, 78, 2227-2246.

64. Griesbeck, A. G., Hoffmann, N., \& Warzecha, K.-D. (2007). Photoinduced-electron-transfer chemistry: From studies on PET processes to applications in natural product synthesis. Accounts of Chemical Research, 40, 128-140.

65. Miller, D. C., Tarantino, K. T., \& Knowles, R. R. (2016). Protoncoupled electron transfer in organic synthesis: Fundamentals, applications, and opportunities. Topics in Current Chemistry, $374,30$.

66. Hoffmann, N. (2017). Proton-coupled electron transfer in photoredox catalytic reactions. European Journal of Organic Chemistry, 2017, 1982-1992.

67. Nguyen, L. Q., \& Knowles, R. R. (2016). Catalytic C-N bondforming reactions enabled by proton-coupled electron transfer activation of amide N-H bondes. ACS Catalysis, 6, 2894-2903.

68. Alonso, R., \& Bach, T. (2014). A Chiral Thioxanthone as an organocatalyst for enantioselective [2+2] photocycloaddition reactions induced by visible light. Angewandte Chemie International Edition, 53, 4368-4371.

69. Li, X., Jandl, C., \& Bach, T. (2020). Visible-light-mediated enantioselective photoreactions of 3-alkylquinolones with 4-O-tethered alkenes and allenes. Organic Letters, 22, 3618-3622. 
70. Skubi, K. L., Kidd, J. B., Jung, H., Guzei, I. A., Baik, M.-H., \& Yoon, T. P. (2017). Enantioselective excited-state photoreactions controlled by a chiral hydrogen-bonding iridium sensitizer. Journal of the American Chemical Society, 139, 17186-17192.

71. Cauble, D. F., Lynch, V., \& Krische, M. J. (2003). Studies on the enantioselective catalysis of photochemically promoted transformations: "sensitizing receptors" as chiral catalysts. Journal of Organic Chemistry, 68, 15-21.

72. Li, X., Großkopf, J., Jandl, C., \& Bach, T. (2021). Enantioselective, visible light mediated aza Paternò-Büchi reactions of quinoxalinones. Angewandte Chemie International Edition, 60, 2684-2688.

73. Brimioulle, R., \& Bach, T. (2013). Enantioselective lewis acid catalysis of intramolecular enone [2+2] photocycloaddition reactions. Science, 342, 840-843.

74. Zhang, C., Chen, S., Ye, X.-X., Harms, K., Zhang, L., Houk, K. N., \& Meggers, E. (2019). Asymmetric photocatalysis by intramolecular hydrogen-atom transfer in photoexcited catalystsubstrate complex. Angewandte Chemie International Edition, $58,14462-14466$.

75. Xia, W., Shao, Y., Gui, W., \& Yang, C. (2011). Efficient synthesis of polysubstituted isochromanones via a novel photochemical rearrangement. Chemical Communications, 47, 11098-11100. The same unusual reaction was carried out under UV irradiation without metal complexation or chiral induction.

76. Huang, X., Li, X., Xie, X., Harms, K., Riedel, R., \& Meggers, E. (2017). Catalytic asymmetric synthesis of a nitrogen heterocycle through stereocontrolled direct photoreaction form the electronically excited state. Nature Communications, 8, 2245.

77. Nakafuku, K. M., Zhang, Z., Wappes, E. A., Stateman, L. M., Chen, A. D., \& Nagib, D. A. (2020). Enantioselective radical $\mathrm{C}-\mathrm{H}$ amination for the synthesis of $\beta$-amino alcohols. Nature Chemistry, 12, 697-704.

78. Seebach, D., Beck, A. K., \& Heckel, A. (2001). TADDOLs, their derivatives, and TADDOL analogues: versatile chiral auxiliaries. Angewandte Chemie International Edition, 40, 92-138.

79. Wang, W., Clay, A., Krishnan, R., Lajkiewisz, N. J., Brown, L. E., Sivaguru, J., \& Porco, J. A., Jr. (2017). Total syntheses of isomeric aglain natural products foveoglin A and perviridine B: Excited-state intramolecular proton-transfer photocycloaddition. Angewandte Chemie International Edition, 56, 14479-14482.

80. Roche, S. P., Cencic, R., Pelletier, J., \& Porco, J. A., Jr. (2010). Biomimetic photocycloaddition of 3-Hydroxyflavones: Synthesis and evaluation of rocaglate derivatives as inhibitors of eukariotic translation. Angewandte Chemie International Edition, 49, 6533-6538.

81. McMorrow, D., \& Kasha, M. (1984). Intramolecular excited-state proton transfer in 3-hydroxyflavone. Hydrogen-bonding solvent perturbations. Journal of Physical Chemistry, 88, 2235-2243.

82. Bader, A. N., Pivovarenko, V. G., Demchenko, A. P., Ariese, F., \& Gooijer, C. (2004). Excited state and ground state proton transfer rates of 3-hydroxyflavone and its derivatives studied by Shpol'skii spectroscopy: The influence of redistribution of electron density. The Journal of Physical Chemistry B, 108, 10589-10595.

83. Rono, L. J., Yayla, H. G., Wang, D. Y., Armstrong, M. F., \& Knowles, R. R. (2013). Enantioselective photoredox catalysis enabled by proton-coupled electron transfer: Development of an asymmetric aza-pinacol cyclization. Journal of the American Chemical Society, 135, 17735-17738.

84. Gentry, E. C., \& Knowles, R. R. (2016). Synthetic applications of proton-coupled electron transfer. Accounts of Chemical Research, 49, 1546-1556.

85. Roos, C. B., Demaerel, J., Graff, D. E., \& Knowles, R. R. (2020). Enantioselective hydroamination of alkenes with sulfonamides enabled by proton-coupled electron transfer. Journal of the American Chemical Society, 142, 5974-5979.
86. Heller, B., \& Hapke, M. (2007). The fascinating construction of pyridine ring systems by transition metal-catalysed $[2+2+2]$ cycloaddition reactions. Chemical Society Reviews, $36,1085-1094$.

87. Schulz, W., Pracejus, H., \& Oehme, G. (1989). Photoassisted cocyclization of acetylene and nitriles catalyzed by cobalt complexes at ambient temperature and normal pressure. Tetrahedron Letters, 30, 1229-1232.

88. Heller, B., Heller, D., \& Oehme, G. (1996). Systematic investigation of the photocatalytic alkyne-nitrile heterotrimerisation to pyridine. Journal of Molecular Catalysis A, 110, 211-219.

89. Heller, B., Sudermann, B., Fischer, C., You, J., Chen, W., Drexler, H.-J., Knochel, P., Bonrath, W., \& Gutnov, A. (2003). Facile and racemization-free conversion of chiral nitriles into pyridine derivatives. Journal of Organic Chemistry, 68 , 9221-9225.

90. Heller, B., Sudermann, B., Buschmann, H., Drexler, H.-J., You, J., Holzgrabe, U., Heller, E., \& Oehme, G. (2002). Photocatalyzed $[2+2+2]$-cycloaddition of nitriles with acetylene: An effective method for the synthesis of 2-pyridines under mild conditions. Journal of Organic Chemistry, 67, 4414-4422.

91. Gutnov, A., Heller, B., Fischer, C., Drexler, H.-J., Spannenberg, A., Sundermann, B., \& Sundermann, C. (2004). Cobalt(I)-catalysed $[2+2+2]$ cycloaddition of alkynes and nitriles: Synthesis of enantiomerically enriched atropoisomers of 2-arylpyridines. Angewandte Chemie International Edition, 43, 3795-3797.

92. Kumarasamy, E., Ayitou, A.J.-L., Vallavoju, N., Raghunathan, R., Iyer, A., Clay, A., Kanadappa, S. K., \& Sivaguru, J. (2016). Tale of twisted molecules. Atropslective photoreactions: taming light induced asymmetric transformations through non-biaryl atropisomers. Accounts of Chemical Research, 49, 2713-2724.

93. Drauz, K., Gröger, H., \& May, O. (Eds.). (2012). Enzyme catalysis in organic synthesis (3rd ed.). Wiley-VCH.

94. Ni, Y., \& Hollmann, F. (2016). Artificial Photosynthesis: Hybrid Systems. Advances in Biochemical Engineering/Biotechnology, 159, 137-158.

95. Maciá-Agulló, J. A., Corma, A., \& Garcia, J. (2015). Photocatalysis: The power of combining photocatalysis and enzymes. Chemistry: A European Journal, 21, 10940-10959.

96. Burek, B. O., Bormann, S., Hollmann, F., Bloh, J. Z., \& Holtmann, D. (2019). Hydrogen peroxide driven biocatalysis. Green Chemistry, 21, 3232-3249.

97. Hollmann, F., Kara, S., Opperman, D. J., \& Wang, Y. (2018). Biocatalytic synthesis of lactones and lactams. Chemistry - An Asian Journal, 13, 3601-3610.

98. Alphand, V., \& Wohlgemuth, R. (2010). Application of BaeyerVilliger monooxygenase in organic synthesis. Current Organic Chemistry, 14, 1928-1965.

99. Mihovilovic, M. D. (2006). Enzyme mediated Baeyer-Villiger oxidations. Current Organic Chemistry, 10, 1265-1287.

100. Mihovilovic, M. D., Müller, B., \& Stanetty, P. (2002). Monooxygenase-mediated Baeyer-Villiger oxidations. European Journal of Organic Chemistry, 2002, 3711-3730.

101. Hollmann, F., Taglieber, A., Schulz, F., \& Reez, M. T. (2007). A light-driven stereoselective biocatalytic oxidation. Angewandte Chemie International Edition, 46, 2903-2906.

102. Krow, G. R. (1993). The Baeyer-Villiger oxidation of ketones and aldehydes. Organic Reactions, 43, 251-798.

103. Renz, M., \& Meunier, B. (1999). 100 Years of Baeyer-Villiger oxidations. European Journal of Organic Chemistry, 1999, 737-750.

104. Gargiulo, S., Arends, I. W. C. E., \& Hollmann, F. (2011). A photoenzymatic system, for alcohol oxidation. ChemCatChem, 3, 338-342. 
105. Kroutil, W., Mang, H., Edegger, K., \& Faber, K. (2004). Biocatalytic oxidation of primary and secondary alcohols. Advanced Synthesis \& Catalysis, 346, 125-142.

106. Rauch, M., Schmidt, S., Arends, I. W. C. E., Oppelt, K., Kara, S., \& Hollmann, F. (2017). Photobiocatalytic alcohol oxidation using LED light sources. Green Chemistry, 19, 376-379.

107. Biegasiewicz, K. F., Cooper, S. J., Gao, X., Oblinsky, D. G., Kim, J. H., Garfinkle, S. E., Joyce, L. A., Sandoval, B. A., Scholes, G. D., \& Hyster, T. K. (2019). Photoexcitation of flavoenzymes enables a stereoselective radical cyclization. Science, 364, $1166-1169$.

108. Black, M. J., Biegasiewicz, K. F., Meichan, A. J., Oblinsky, D. G., Kudisch, B., Scholes, G. D., \& Hyster, T. K. (2020). Asymmetric redox-neutral radical cyclization catalysed by flavinedependent 'ene'-reductases. Nature Chemistry, 12, 71-75.

109. Gritsch, P. J., Leitner, C., Pfaffenbach, M., \& Gaich, T. (2014). The Witkop cyclization: A photoinduced $\mathrm{C}-\mathrm{H}$ activation of the indole system. Angewandte Chemie International Edition, 53, 1208-1217.

110. Zhang, W., Fernandez Fueyo, E., Hollmann, F., Leemans Martin, L., Pesic, M., Wardenga, R., Höhne, M., \& Schmidt, S. (2019). Combining photo-organo redox- and enzyme catalysis facilitates asymmetric C-H bond functionalization. European Journal of Organic Chemistry, 2019, 80-84.

111. Page, C. G., Cooper, S. J., DeHovitz, J. S., Oblinsky, D. G., Biegasiewicz, K. F., Antonow, A. H., Armbrust, K. W., Ellis, J. M., Hamann, L. G., Horn, E. J., Oberg, K. M., Scholes, G. D., \& Hyster, T. K. (2021). Quarternary charge-transfer complex enables photoenzymatic intermolecular hydroalkylation of olefins. Journal of the American Chemical Society, 143, 97-102.

112. Sandoval, B. A., Clayman, P. D., Oblinsky, D. G., Oh, S., Nakano, Y., Bird, M., Scholes, G. D., \& Hyster, T. K. (2021). Photoenzymatic reductions enabled by direct excitation of flavindependent "ene"-reductases. Journal of the American Chemical Society, 143, 1735-1739.

113. Chen, J., Guan, Z., \& He, Y.-H. (2019). Photoenzymatic approaches in organic synthesis. Asian Journal of Organic Chemistry, 8, 1775-1790.

114. Jacques, J., Collet, A., \& Wilen, S. H. (1994). Enantiomers, racemates, and resolutions. Krieger Publishing Com. Copyright 1981, John Wiley \& Sons, Inc.

115. Nespolo, M., Aroyo, M. I., \& Souvignier, B. (2018). Crystallographic shelves: Space-group hierarchy explained. Journal of Applied Crystallography, 51, 1481-1491.

116. Levkin, P. A., Torbeev, V. Y., Lenev, D. A., \& Kostyanovsky, R. G. (2006). Homo- and heterochirality in crystals. Topics in Stereochemistry, 25, 81-134.

117. Sakamoto, M. (2006). Spontaneous chiral crystallization of achiral materials and absolute asymmetric photochemical transformation using the chiral crystalline environment. Journal of Photochemistry and Photobiology C: Photochemistry Reviews, 7, 183-196.

118. Kuroda, R. (2004). Circular dichroim in the solid state. In Y. Inoue \& V. Ramamurthy (Eds.), Chiral photochemistry (pp. 385-413). Marcel Dekker

119. Green, B. S., Lahav, M., \& Rabinonvich, D. (1979). Asymmetric synthesis via reaction in chiral crystals. Accounts of Chemical Research, 12, 191-197.

120. Toda, F., Yagi, M., \& Soda, S.-I. (1987). Formation of a chiral $\beta$-lactam by photocyclisation of an achiral oxo amide in its chiral crystalline state. Journal of the Chemical Society, Chemical Communications, 18, 1413-1414.

121. Toda, F., \& Miyamoto, H. (1993). Formation of chiral $\beta$-lactams by photocyclisation of achiral N, N-diisopropylarylglyoxylamides in their chiral crystalline form. Journal of the Chemical Society Perkin Transactions, I, 1129-1132.
122. Sekine, A., Hori, K., Ohashi, Y., Yagi, M., \& Toda, T. (1989). $\mathrm{X}$-ray Structural studies of chiral $\beta$-lactam formation from an achiral oxo amide using the chiral-crystal environment. Journal of the American Chemical Society, 111, 697-699.

123. Sakamoto, M., Takahashi, M., Kamiya, K., Yamaguchi, K., Fujita, T., \& Watanabe, S. (1996). Crystal-to-crystal solid-state photochemistry: absolute asymmetric $\beta$-thiolactam synthesis from an achiral $\alpha, \beta$-unsaturated thioamide. Journal of the American Chemical Society, 118, 10664-10665.

124. Sakamoto, M., Kimura, M., Shimoto, T., Fujita, T., \& Watanabe, S. (1990). Photochemical reaction of N, N-dialkyl- $\alpha$, $\beta$-unsaturated thioamides. Journal of the Chemical Society, Chemical Communications, 18, 1214-1215.

125. Sakamoto, M., Takahashi, M., Arai, W., Mino, T., Yamaguchi, K., Watanabe, S., \& Fujita, T. (2000). Solid-state photochemistry: absolute asymmetric $\beta$-thiolactam synthesis from achiral $\mathrm{N}, \mathrm{N}$-dibenzyl- $\alpha, \beta$-unsaturated thioamides. Tetrahedron, 56 , 6795-6804.

126. Kellogg, R. M. (2017). Practical stereochemistry. Accounts of Chemical Research, 50, 905-914.

127. Veeman, M., Resendiz, M. J. E., \& Garcia-Garibay, M. A. (2006). Large-scale photochemical reactions of nanocrystalline suspensions: A promising green chemistry method. Organic Letters, 8 , 2615-2617.

128. Scheffer, J. R., \& Xia, W. (2005). Asymmetric induction in organic photochemistry via the solid-state ionic chiral auxiliary approach. Topics in Current Chemistry, 254, 233-262.

129. Natarajan, A., Wang, K., Ramamurthy, V., Scheffer, J. R., \& Patrick, B. (2002). Control of enantioselectivity in the photochemical conversion of $\alpha$-oxoamides into $\beta$-lactam derivatives. Organic Letters, 4, 1443-1446.

130. Galindo, F. (2005). The photochemical rearrangement of aromatic ethers A review of the Photo-Claisen reaction. Journal of Photochemistry and Photobiology C: Photochemistry Reviews, 6, 123-138.

131. Xia, W., Yang, C., Patrick, B. O., Scheffer, J. R., \& Scott, C. (2005). Asymmetric synthesis of dihydrofurans via a formal retro-claisen photorearrangement. Journal of the American Chemical Society, 127, 2725-2730.

132. Frénau, M., \& Hoffmann, N. (2017). The Paternò-Büchi reaction-Mechanisms and application to organic synthesis. Journal of Photochemistry and Photobiology C: Photochemistry Reviews, $33,83-108$.

133. D'Auria, M. (2019). The Paternò-Büchi reaction-A comprehensive review. Photochemical \& Photobiological Sciences, 18, $2297-2362$.

134. Abe, M. (2010). Formation of a four-membered ring: Oxetanes. In A. Albini \& M. Fagnoni (Eds.), Handbook of synthetic photochemistry (pp. 217-239). Wiley-VCH.

135. Buschmann, H., Scharf, H.-D., Hoffmann, N., Plath, M. W., \& Runsink, J. (1989). Chiral induction in photochemical reactions. 10. The principle of isoinversion: A model of stereoselection developed from the diastereoselectivity of the Paternò-Büchi reaction. Journal of the American Chemical Society, 111, 5367-5373.

136. Toda, F. (1988). Reaction control of guest compounds in hostgest inclusion complexes. Topics in Current Chemistry, 149, 211-238.

137. Koshima, H. (2004). Chiral solid-state photochemistry including supramolecular approaches. In Y. Inoue \& V. Ramamurthy (Eds.), Chiral photochemistry (pp. 485-531). Marcel Dekker.

138. Tanaka, K., \& Toda, F. (2000). Solvent-free organic synthesis. Chemical Reviews, 100, 1025-1074.

139. Toda, F., Miyamoto, H., Kanemoto, K., Tanaka, K., Takahashi, Y., \& Takenaka, Y. (1999). Enantioselective photocyclization of $\mathrm{N}$-alkylfuran-2-carboxanilides to trans-dihydrofuran derivatives 
in inclusion crystals with optically active host compounds derived from tartaric acid. Journal of Organic Chemistry, 64, 2096-2102.

140. Jennings, W. B., Farrell, B. M., \& Malone, J. F. (2001). Attractive intramolecular edge-to-face interactions in flexible organic molecules. Accounts of Chemical Research, 34, 885-894.

141. Rekharsky, M. V., \& Inoue, Y. (1998). Complexation thermodynamics of cyclodextins. Chemical Reviews, 98, 1875-1918.

142. Del Valle, E. M. (2004). Cyclodextins and their uses: A review. Process Biochemistry, 39, 1033-1046.

143. Morin-Crini, N., Fourmentin, S., \& Crini, G. (2015). Cyclodextrines-Histoire, propriétés, chimie \& applications. Presses universitaires de Franche-Compté.

144. Mansour, A. T., Buendia, J., Xie, J., Brisset, F., Robin, S., Naoufal, D., Yazbeck, O., \& Aitken, D. J. (2017). $\beta$-Cyclodextinmediated enantioselective photochemical electrocyclization of 1,3-dihydro-2H-azepin-2-one. Journal of Organic Chemistry, 82, 9832-9836.

145. Weitkamp, J., \& Puppe, L. (Eds.). (1999). Catalysis and zeolites. Springer.

146. Chester, A. W., \& Derouane, E. G. (Eds.). (2009). Zeolite characterization and catalysis. Springer.

147. Pérez Pariente, J., \& Sánchez-Sánchez, M. (Eds.). (2018). Structure and reactivity of metals in zeolite materials. Springer Nature.

148. Ramamurthy, V. (2019). Achiral zeolites as reaction media for chiral photochemistry. Molecules, 24, 3570.

149. Sivaguru, S., Nathrajan, A., Kaanumalle, L. S., Shailalja, S., Uppili, S., Joy, A., \& Ramamurthy, V. (2003). Asymmetric photoreactions within zeolites: Role of confinement and alkali metal ions. Accounts of Chemical Research, 36, 509-521.

150. Scaiano, S. C., \& García, M. (1999). Intrazeolite Photochemistry: Toward Supramolecular Control of Molecular Photochemistry. Accounts of Chemical Research, 32, 783-793.

151. Sivasubrmanian, K., Kaanumalle, L. S., Uppili, S., \& Ramamurthy, V. (2007). Value of zeolites in asymmetric induction during photocyclization of pyridines, cyclohexadiones and naphthalenones. Organic \& Biomolecular Chemistry, 7, 1569-1576.

152. Ruch, E., \& Ugi, I. (1969). The stereochemical analogy modelA mathematical theory of dynamic stereochemistry. Topics in Stereochemistry, 4, 99-125.

153. Alezra, V., \& Kawabata, T. (2016). Recent progress in memory of chirality (MOC): An advanced chiral pool. Synthesis, 48, 2997-3016.

154. Zhao, H., Hsu, D. C., \& Carlier, P. R. (2005). Memory of chirality: An emerging strategy for asymmetric synthesis. ChemInform. https://doi.org/10.1002/chin.200516265.

155. Gloor, C. S., Dénès, F., \& Renaud, P. (2016). Memory in reactions involving monoradicals. Free Radical Research, 50, S102-S111.

156. Kramer, W. H., \& Griesbeck, A. G. (2008). The same and not the same: Chirality, topicity, and memory of chirality. Journal of Chemical Education, 85, 701-709.

157. Griesbeck, A. G., Kramer, W., \& Lex, J. (2001). Diastereoand enantioselective synthesis of pyrrolo[1,4]benzodiazepines through decarboxylative photocyclization. Angewandte Chemie International Edition, 40, 577-579.

\section{Authors and Affiliations}

\section{Norbert Hoffmann ${ }^{1}$ (D)}

Norbert Hoffmann

norbert.hoffmann@univ-reims.fr
158. Salem, L., \& Rowland, C. (1972). The electronic properties of diradicals. Angewandte Chemie International Edition, 11, 92-111.

159. Carlacci, L., Doubleday, D., Jr., Furlani, T. R., King, H. F., \& McIver, J. W., Jr. (1987). Spin-orbit coupling in biradicals. $\mathrm{Ab}$ initio MCSCF calculations on trimethylene and the methylmethyl radical pair. Journal of the American Chemical Society, 109, 5323-5329.

160. Michl, J. (1996). Spin-orbit coupling of biradicals. 1. The 2-electron-in-2-orbitals model revisited. Journal of the American Chemical Society, 118, 3568-3579.

161. Griesbeck, A. G., Abe, M., \& Bondock, S. (2004). Selectivity control in electron spin inversion processes: Regio- and stereochemistry of Paternò-Büchi photocycloadditions as a powerful tool for mapping intersystem crossing processes. Accounts of Chemical Research, 37, 919-928.

162. Griesbeck, A. G., Mauder, H., \& Stadtmüller, S. (1994). Intersystem crossing in triplett 1,4-biradicals: conformational memory effects on the stereoselectivity of photocycloaddition reactions. Accounts of Chemical Research, 27, 70-75.

163. Wanyoike, G. N., Onomura, O., Maki, T., \& Matsumura, Y. (2002). Highly enhanced enantioselectivity in the memory of chirality via acyliminium ions. Organic Letters, 4, 1875-1877.

164. Onomura, O. (2016). Aliphatic nitrogen-containing compounds, amines, amino alcohols, and amino acids. In O. Hammerich \& B. Speiser (Eds.), Organic electrochemistry (5th Edition) (pp. 1103-1119). CRC Press.

165. Šumanovac Ramljak, T., Sohora, M., Antol, I., Kontrec, D., Basarić, N., \& Mlinarić-Majerski, K. (2014). Memory of chirality in the phthalimide photocyclization. Tetrahedron Letters, 55, 4078-4081.

166. Sinicropi, A., Barbosa, F., Basosi, R., Giese, B., \& Olivucci, M. (2005). Mechanism of the Norrish-Yang Photocyclization reaction of an alanine derivative in the singlet state: Origin of the chiral-memory effect. Angewandte Chemie International Edition, 44, 2390-2393.

167. Sakamoto, M., Kawanishi, H., Mino, T., Kasashima, Y., \& Fujita, T. (2006). Photochemcial asymmetric synthesis of phenyl-bearing quaternary chiral carbons using chiral-memory effect on $\beta$-hydrogen abstraction by thiocarbonyl group. Chemical Communications, 44, 4608-4610.

168. Bonache, M. A., López, P., Martín-Martínez, M., García-López, M. T., Cativiela, C., \& González-Muñiz, R. (2006). Stereoselective synthesis of amino acid-derived $\beta$-lactams. Experimental evidence for TDDOL as a memory of chirality enhancer. Tetrahedron, 62, 130-138.

169. Mori, T., Saito, H., \& Inoue, Y. (2003). Complete memory of chirality upon photodecarboxylation of mesityl alkanoate to mesitylalkane: Theoretical and experimental evidence for cheletropic decarboxylation via a spiro-lactonic transition state. Chemical Communications, 18, 2302-2303.

170. Bhattacharyya, A., De Sarkar, S., \& Das, A. (2021). Supramolecular engineering and self-assembly strategies in photoredox catalysis. ACS Catalysis, 11, 710-733.

171. Baruah, J. B. (2019). Principles and advances in supramolecular catalysis. CRC Press.
1 ICMR, Equipe de Photochimie, UFR Sciences, CNRS, Université de Reims Champagne-Ardenne, B.P. 1039, 51687 Reims, France 